J. Lake Sci. (湖泊科学), 2019, 31(6): 1637-1650

DOI 10. 18307/2019. 0604

(c) 2019 by Journal of Lake Sciences

\title{
辽河流域太子河大型底栖动物群落与水环境因子关联性的量化 分析
}

孟云飞 ${ }^{1}$, 崔恩慧 ${ }^{1}$, 鲁 甲 ${ }^{1}$, 殷旭旺 ${ }^{1 * *}$, 徐宗学 ${ }^{2}$, 张 远 $^{3}$

(1: 大连海洋大学水产与生命学院, 辽宁省水生生物学重点实验室, 大连 116023)

(2: 北京师范大学水科学研究院, 北京 100875$)$

(3: 中国环境科学研究院,环境基准与风险评估国家重点实验室,流域水生态保护技术研究室,北京 100012)

摘 要: 大型底栖动物群落结构与水环境因子具有较强的响应关系, 为了量化分析大型底栖动物群落水环境因子适宜状 态以及响应关系, 在太子河进行 3 次流域水生态调查, 共获得 136 个站位的生态数据, 通过篮选得到水环境驱动因子, 并 利用加权平均回归分析和临界点指示类群分析的方法, 探究大型底栖动物群落物种、不同多样性水平以及功能摄食类群 水环境驱动因子的最适值和阈值. 结果显示, 显著影响大型底栖动物群落结构的水环境因子是溶解氧、电导率、总氮. 大 型底栖动物敏感种的溶解氧最适值较高, 耐污种较低; 敏感种的电导率和总氮最适值较低, 耐污种较高; 大型底栖动物群 落多样性水平 Shannon-Wiener 指数 (0-1] 区间的溶解氧最适值最低, (3-4] 区间的溶解氧最适值最高, 各 Shannon-Wiener 指数区间电导率和总氮最适值排序为: $(0-1]$ 区间 $<(1-2]$ 区间 $<(2-3]$ 区间 $<(3-4]$ 区间; 在 5 个功能摄食类群中溶解氧 最适值最高和最低分别为撕食者和直接收集者, 电导率最适值最高和最低分别为直接收集者和过滤收集者, 总氮最适值 最高和最低分别为直接收集者和刮食者. 大型底栖动物敏感种的溶解氧阈值高于耐污种类群与其他物种, 而敏感种的电 导率和总氮阈值低于耐污种和其他物种; 大型底栖动物群落多样性水平 Shannon-Wiener 指数 (0-1] 区间与溶解氧间值呈 负响应关系，而与电导率和总氮阈值呈正响应关系，(1-2]区间、(2-3]区间、(3-4]区间与溶解氧阈值呈正响应关系, 而 与电导率和总氮阈值呈负响应关系; 溶解氧指示的大型底栖动物功能摄食类群为撕食者, 且呈正响应关系, 而电导率和 总氮指示的功能摄食类群都包括过滤收集者、刮食者、撕食者, 且呈负响应关系, 其中刮食者的电导率和总氮阈值均最高. 研究表明, 通过分析大型底栖动物群落水环境因子的最适值和阈值, 能以数据的形式量化反映大型底栖动物群落与河流 水环境因子的响应关系,对河流生态环境的保护和修复具有重要的指导意义.

关键词: 太子河; 大型底栖动物; 摄食功能群; 最适值; 阈值

\section{Quantitative analysis of the relationship between benthic macroinvertebrate community and water environment factors in Taizi River, Liaohe River catchment}

MENG Yunfei ${ }^{1}$, CUI Enhui ${ }^{1}$, LU Jia $^{1}$, YIN Xuwang ${ }^{1 * *}$, XU Zongxue $^{2} \&$ ZHANG Yuan ${ }^{3}$

(1: Liaoning Provincial Key Laboratory for Hydrobiology, College of Fisheries and Life Science, Dalian Ocean University, Dalian 116023, P.R.China)

(2: College of Water Science, Beijing Normal University, Beijing 100875, P.R.China)

(3: Laboratory of Riverine Ecological Conservation and Technology, Chinese Research Academy of Environmental Sciences, Beijing 100012, P.R.China)

Abstract: The community structure of benthic macroinvertebrate respond sensitively to water environment. According to the community structure characteristics, the ecological condition of the watershed can be evaluated, and vice versa. At present, the research on benthic macroinvertebrate community structure and water environment was mostly qualitatively studied, which could not

* 辽宁省优秀人才支持计划项目 (LR2015009)、国家自然科学基金项目 (41977193) 和辽宁省 “兴辽英才计划” 项目 (XLYC1807228) 联合资助. 2019-01-13 收稿;2019-03-31 收修改稿. 孟云飞(1991 ), 男, 硕士研究生; E-mail: mengyunfei0830@163.com.

** 通信作者;E-mail : yinxuwang@ dlou.edu.cn. 
accurately reflect their quantitative relationship. In order to quantify such relationship, we conducted three ecological surveys in the Taizi River, and obtained ecological data from 136 stations. We obtained the habitat water environment driving factors through screening, and used weighted average (WA) and thresholds indicator taxa analysis (TITAN) to analyze optimal values (OV) and threshold of indicator species (group) of driving factors for water environment in benthic macroinvertebrate (BM) community, different diversity levels and feeding function group. The results showed that the driving factors of the BM community were dissolved oxygen, conductivity, and total nitrogen (TN). The sensitive BM community have high OV in dissolved oxygen, while the pollution-tolerance species has low OV. The sensitive BM community also have lower OV in conductivity and TN, while the pollutiontolerance species has higher values. The lowest dissolved oxygen OV in the Shannon-Wiener index $(0-1]$ interval, and the highest dissolved oxygen $\mathrm{OV}$ in the (3-4] interval. The OV of conductivity and TN in each group were ranked as follows: $(0-1]$ interval< (1-2] interval $<(2-3]$ interval $<(3-4]$ interval. In the five functional feeding groups, the highest and the lowest dissolved oxygen $\mathrm{OV}$ were the shredders and the gatherer-collectors, the highest and the lowest conductivity $\mathrm{OV}$ were the gatherer-collectors and the filterer-collectors, and the highest and the lowest TN OV were the gatherer-collectors and the scrapers. The dissolved oxygen threshold of BM sensitive species were higher than that of pollution-tolerant species and other species, while the sensitive species of conductivity and TN threshold were lower than that of pollution-tolerant species and other species; The Shannon-Wiener index (0-1] interval had a negative relationship with threshold of dissolved oxygen, and positively relationship with threshold of conductivity and $\mathrm{TN}$; while the Shannon-Wiener index intervals of (1-2], (2-3] and (3-4] had a positive relationship with the threshold of dissolved oxygen and a negative relationship with the conductivity and TN. The BM feeding function groups (FFGs) indicated by dissolved oxygen was shredders, and had a positively relationship with the threshold of dissolved oxygen, while the feeding function groups indicated by conductivity and TN include filterer-collectors, scrapers and shredders, and had a negative relationship. The scrapers' conductivity and TN threshold were the highest. The study showed that analyzing the optimum value and threshold value of the aquatic environmental factors of the BM community, the relationship between the BM community and the aquatic environmental factors of the river can be quantified, which had important guiding significance for the protection and restoration of the river ecological environment.

Keywords: Taizi River; benthic macroinvertebrate; feeding function groups(FFGs); optimal value; thresholds

水环境因子是河流生态系统重要的构成部分, 其直接或间接影响水生生物群落结构和空间分布 ${ }^{[1-3]}$; 保 持水生生物生存的水环境处于适宜状态, 维持生物多样性和生态系统稳定性的基础. 近年来, 人类活动对河 流栖境水环境造成了不同程度的影响, 导致水生生物群落生物多样性丧失和生物完整性破坏, 甚至影响河 流生态系统的稳定性 ${ }^{[4]}$. 因此, 研究和评价水生生物群落的物种、多样性水平、功能群特征等与水环境因子 的响应关系, 确定维持生物多样性以及生态系统稳定性的适宜环境状况, 是开展河流生态保护和修复, 提高 河流生态系统服务价值的重要途径.

河流生态学研究中, 水生生物群落结构与环境因子的关联性一直都是热点问题; 研究表明, 鱼类、大型 底栖动物、着生藻类等水生生物群落结构特征及其空间分布与河流生境状态具有较强的响应关系 ${ }^{[5-7]}$; 其中 大型底栖动物生命周期较长、迁移能力较差、对栖息地环境变化具有累积反应等特征 ${ }^{[8]}$, 是河流生态学研究 的经典模式生物类群 ${ }^{[9]}$. 大型底栖动物易受环境因子变化的影响, 河流营养物质和污染物的增加, 可加剧水 环境中溶解氧浓度降低, 导致大型底栖动物敏感种减少, 耐污种增加, 甚至只有耐污种存在 ${ }^{[10-11]}$; 研究表明, 电导率对大型底栖动物的存活存在毒性效应, 电导率的升高显著降低了大型底栖动物敏感种的出现频 率 ${ }^{[12]}$; 龚志军等研究发现, 大型底栖动物群落多样性与水体富营养化水平呈负相关的趋势, 富营养化导致多 样性明显降低 ${ }^{[13]}$. 目前关于大型底栖动物与水环境因子的研究大多集中于定性分析水生生物的群落结构 与环境因子的关联性, 不能体现群落适宜的水环境因子指标水平以及引起群落结构变化的水环境因子临界 点; 为了深人了解河流水环境因子对水生生物群落结构的影响, 定量研究水生生物群落与水环境因子的响 应关系就显得尤为重要.

目前, 国内外关于水生生物环境因子的定量研究, 主要通过建立适宜度指数模型和加权平均回归分析 的方法分析物种的环境因子最适值 ${ }^{[14-16]}$, 或利用非参数转变点分析方法和阈值指示分类群分析法分析物种 的环境因子阈值 ${ }^{[17-19]}$. 环境因子的最适值是指研究对象最适生存条件下环境因子的值, 而阈值是指引起生 态系统质量、性质或现象发生突变的一个或多个环境因子对应的点 ${ }^{[20]}$, 将水生生物群落环境因子最适值和 
阈值相结合, 可更准确评价水生生物群落栖境适宜性的需求. 物种是群落组成的最小单元, 反映群落的基本 特征; 而生物多样性既能反映生物群落特征, 同时又是河流生态健康评价中重要的生物指标之一 ${ }^{[21]}$; 此外, 功能摄食类群将生态系统中的有机物、营养源和高级生物以食物链的形式联系起来, 反映河流生态系统的 营养水平和功能组成 ${ }^{[22]}$. 将最适值和阈值有机结合起来综合探究水生生物群落的物种、多样性水平和功能 摄食类群多样性水环境梯度压力下需求的最适宜水平和阈值响应状态, 对了解水生生物群落与水环境因子 的响应关系、生物多样性保护、生态修复以及流域污染物总量控制等具有重要的科学价值 ${ }^{[23]}$. 本研究以太 子河为范例, 基于大型底栖动物群落, 利用加权平均回归分析 (weighted average, WA) 和临界点指示类群分 析法 ( thresholds indicator taxa analysis, TITAN), 分析大型底栖动物群落的物种、多样性水平以及功能摄食类 群所对应的水环境因子的最适值和阈值, 量化大型底栖动物群落水环境驱动因子的压力响应, 以期为太子 河流域的污染物控制、生态治理以及水环境保护提供理论数据支持.

\section{1 材料与方法}

\section{1 研究区域及站位设置}

太子河流域 $\left(40^{\circ} 30^{\prime} \sim 41^{\circ} 40^{\prime} \mathrm{N}, 122^{\circ} 30^{\prime} \sim 124^{\circ} 50^{\prime} \mathrm{E}\right.$ ) 位于我国辽宁省东部, 发源于辽宁省新宾县境内的 长白山脉; 向西流经本溪、鞍山、辽阳三市, 在三岔河与浑河一起汇人大辽河, 行至营口市注人渤海; 流域面 积 $1.4 \times 10^{4} \mathrm{~km}^{2}$, 干流全长 $413 \mathrm{~km}$, 年均径流量 $37.7 \times 10^{8} \mathrm{~m}^{3}$; 属温带季风气候, 年温差大, 最高温在 $7-8$ 月, 最低温在 1-2 月; 上游为山地溪流类型, 海拔相对较高, 森林覆盖率较高, 受到的人为活动影响较小; 中、下 游为丘陵河流区和平原河流区, 土地开发程度较高, 城镇化以及工业化影响较高, 水质恶化相对较严重. 太 子河流域上游至下游受人为干扰影响, 水环境质量变化明显, 为本研究提供了良好的水环境指标梯度变化 条件;2012 年 5 月对太子河整体普查, 2016 年 9 月和 2018 年 4 月主要是对太子河本溪市城区及其周边人为 干扰较大、污染较为严重区域的水生态调查; 综合 3 次 (共 136 个站位) 全流域的调查结果, 保证了样本量的 充足,同时也提高了研究结果的可靠性.

太子河水生态调查站位设置见图 1,2012 年 5 月在太子河共设置 43 个采样站位 (12T1 12T43); 2016 年 9 月在太子河共设置 40 个采样站位 (16T1、16T2、16T9～16T19、16T21～16T30、16T33～16T35、16T41～ $16 \mathrm{~T} 43 、 16 \mathrm{~T} 45 、 16 \mathrm{~T} 48 \sim 16 \mathrm{~T} 60)$; 2018 年 4 月在太子河共设置 53 个采样站位 $(18 \mathrm{~T} 1 \sim 18 \mathrm{~T} 53 、 18 \mathrm{~T} 60)$.

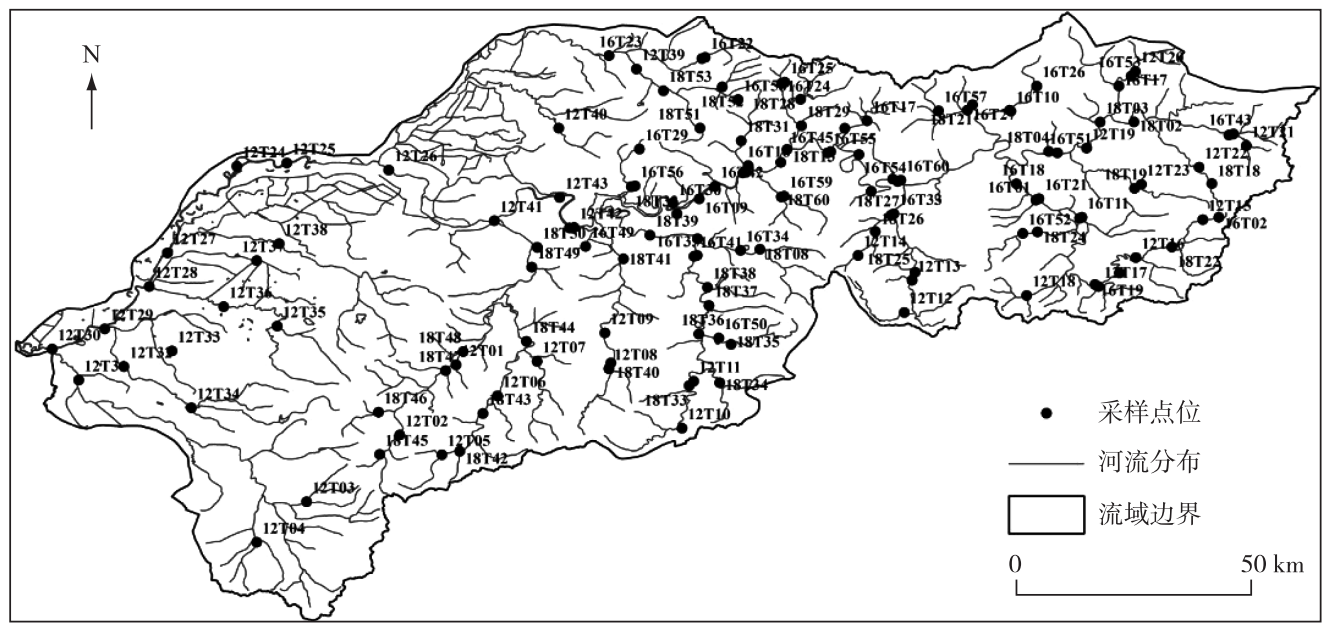

图 1 太子河流域采样站位分布

Fig.1 Distribution of sampling sites in the Taizi River Basin

\section{2 大型底栖动物样品采集、分类与鉴定}

在可涉水的站位,利用索伯网 (surber, 网口为 $30 \mathrm{~cm} \times 30 \mathrm{~cm}$, 网孔径为 $500 \mu \mathrm{m}$ ) 于站位上下游 $100 \mathrm{~m}$ 范 
围内, 选择不同的生境类型采集 3 个平行样本, 而在不可涉水的站位采用彼得逊采泥器 $\left(1 / 16 \mathrm{~m}^{2}\right)$ 进行取样. 每个站位所有采集样品先经过 60 目篮网过滤、洗涤转人到白瓷盘中, 然后经过人工挑拣, 置人到 $100 \mathrm{ml}$ 的 广口塑料瓶中, 同时加人 $95 \%$ 的酒精溶液进行保存、待检; 利用显微镜和解剖镜对大型底栖动物进行物种鉴 定 (尽可能鉴定到种或属)、分类、计数 ${ }^{[24-26]}$, 置于电子天平 $(0.0001 \mathrm{~g})$ 称重, 并做记录.

\section{3 水环境因子的测定}

在每个采样站位用 MAGELLAN 全球定位系统 (eXplorist-200) 记录采样站位的经纬度; 水温 (WT)、pH、 电导率 (COND)、溶解氧 (DO) 等用水质分析仪 (YSI Pro 2000, YSI Incorporated, 美国) 现场测定; 在各个采样 站位采集 $2 \mathrm{~L}$ 水样置于低温保温箱中, 于 $48 \mathrm{~h}$ 内运送回实验室, 根据标准方法《水和废水监测方法》(第 4 版 $)^{[27]}$ 测定总氮 $(\mathrm{TN})$ 、氨氮 $\left(\mathrm{NH}_{3}-\mathrm{N}\right)$ 、总磷 $(\mathrm{TP})$ 和高锰酸盐指数 $\left(\mathrm{COD}_{\mathrm{Mn}}\right)$ 等化学指标.

\section{4 大型底栖动物功能摄食类群的划分}

本研究根据摄食类型可以将太子河流域大型底栖动物分为 5 个功能摄食类群 $(\mathrm{FFGs})^{[28]}$ : 直接收集者 $(\mathrm{GC}) 、$ 过滤收集者 $(\mathrm{FC}) 、$ 、刮食者 $(\mathrm{SC}) 、$ 撕食者 $(\mathrm{SH}) 、$ 、捕食者 $(\mathrm{PR})$ (表 1$)$.

表 1 大型底栖动物功能摄食类群的划分

Tab.1 Classification of benthic macroinvertebrate feeding functional groups

\begin{tabular}{ccc}
\hline 功能摄食类群 & 食物类型 & 食物粒径大小/mm \\
\hline 直接收集者 & 直接收集河流底质有机质颗粒为食 & $0.05 \sim 1.00$ \\
过滤收集者 & 过滤收集水体细小有机质颗粒为食 & $0.01 \sim 1.00$ \\
刮食者 & 刮食固着生物类群为食 & $0.0 \sim 1.00$ \\
撕食者 & 摄取调零物和较大的有机质颗粒为食 & $>1.00$ \\
捕食者 & 捕获其他水生动物为食 & $>0.50$ \\
\hline
\end{tabular}

\section{5 数据统计处理与分析}

环境因子进行主成分分析 (principal component analysis, PCA), 用于篮选太子河主要的水环境因子, 偏 相关分析 (partial correlation test, PCT) 是为了进一步简化水环境因子, 然后选择典范对应分析 ( canonical correspondence analysis, CCA) 确定河流栖境水环境驱动因子 (趋势对应分析 detrended correspondence analysis, DCA , SD 值>2); 计算大型底栖动物群落 Shannon-Wiener 多样性指数并对采样站位进行多样性水 平的划分, 以不同等分组反映不同的群落多样性水平; 根据大型底栖动物摄食类型划分大型底栖动物功能 摄食类群. 利用加权平均回归分析 (WA) 和阈值指示类群分析法 (TITAN) 的方法计算大型底栖动物群落的 物种、不同多样性水平以及功能摄食类群水环境驱动因子的最适值和生态阈值, 其中为了保证运算结果的 可靠性, 选取采样站位出现 $>5$ 个的物种, 进行物种层面最适值和阈值的分析.

WA 分析水环境驱动因子的最适值, 分析方法是假定研究属 (种)或类群在某一环境因子上呈高斯分 布,其最大含量所对应的环境指标值即是该属(种)或类群的最适生态值. WA 计算公式:

$$
k=\sum_{i=1}^{m} y_{k i} x_{i} / \sum_{i=1}^{m} y_{k i}
$$

式中, $x_{i}$ 是采样站位 $i$ 中的环境变量值; $y_{k i}$ 是研究属 (种) 或类群 $k$ 在采样站位 $i$ 中的百分含量; $m$ 是该属 (种) 或类群总采样站位数 ${ }^{[29]}$.

TITAN 分析水环境驱动因子的國值 ${ }^{[19]}$, 其计算过程为:

1) 沿预测变 $x$ 选取 $n$ 个样本单元, 将 $x$ 的唯一值间的中点作为候选突变点进行识别, 定义最小的 $n$ 值来 计算 $\operatorname{InVal}($ 指示物种指数).

2) 对于每一个分类单元: 从分组的样本的上面和每个候选突变点 $\left(x_{j}\right)$ 的下面计算 Indval 分数, 然后比 较 Indval 下方和每个 $x_{j}$ 上方, 保留较大的分数, 接下来通过所有 $x_{j}$ 来识别最大的 Indval, 观测到的突变点 $x_{\mathrm{cp}}$ 是 $x$ 的对应值,最后将分类单元赋予正响应和负响应的含义.

3) 对于每一个 $x$ 的 250 个随机排序重复 2) 中的步骤, 估计得到随机 Indvals 的频率, 观察到的最大 $\operatorname{Indval}(\rho)$ 以及随机 Indvals 值的均值和标准差. 
4 ) 用排序 Indvals 的均值和标准差将观察到的 Indvals 标准化成 $z$ 分数, 用反应组每个类群的 $z$ 分数的总 和来赋值每个候选突变点 $x_{j}$, 将 $\operatorname{Sum}\left(\mathrm{z}^{-}\right)$和 $\operatorname{Sum}\left(\mathrm{z}^{+}\right)$极大值对应的 $x$ 值作为群落水平的突变点.

TITAN 分析大型底栖动物物种、大型底栖动物群落不同多样性水平以及功能摄食类群的突变点, 对突 变点进行自举重抽样分析 (bootstrapping $)^{[18]}$; 根据自举重抽样分析得到突变点的概率 $(<0.05)$ 、自举重抽样 分析中与观察的突变点响应方向一致性 $(\geqslant 0.95)$ 、自举重抽样分析得到突变点的可靠性 $(\geqslant 0.90)$, 篮选出 各个驱动环境因子相应的指示物种 (或群组) ${ }^{[19]}$; 本研究重复抽样 100 次, $50 \%$ 分位数的突变点作为水环境 驱动因子的國值.

利用 CANOCO4.5 进行主成分分析 (PCA) 和典范对应分析 (CCA) ; 偏相关分析(PCT) 在软件 SPSS 20.0 上 进行; Shannon-Wiener 多样性指数利用软件 Biodiversity Professional 2.0 进行计算; 在 R 软件包上,利用 WA 和 TITAN 方法计算大型底栖动物群落栖境水环境驱动因子的最适值和阈值. 其中 PCA、PCT、DCA、CCA、WA、TI$\mathrm{TAN}$ 分析时,对大型底栖动物数据和环境因子数据(除 $\mathrm{pH}$ 以外) 进行 $[\lg (x+1)]$ 转换; 并对数据进行 999 次蒙 特卡洛循环检验 (Monte Carlo test, MCT), 以判定显著影响大型底栖动物群落空间分布特征的水环境因子.

\section{2 结果}

\section{1 大型底栖动物群落组成及水环境驱动因子的篮选}

在太子河 136 个站位共采集得到大型底栖动物 120 属(种), 隶属于 6 纲 12 目 43 科, 水生昆虫 92 种, 占 $76.67 \%$; 软体动物 14 种, 占 $11.67 \%$; 环节动物 8 种, 占 $6.67 \%$; 甲壳动物 6 种, 占 $5.00 \%$.上游山地区, 人为干 扰程度较小, 生境保护较好, 多分布 EPT(蜉蝣目 Ephemeroptera, 襀翅目 Plecoptera, 毛翅目 Trichoptera) 类的 清洁种类, 常见物种有东方蜉 (Ephemera orientalis)、宜兴似动蜉 (Cinygmina yixingensis)、毛蠓属 (Psychoda sp.) ; 中游丘陵区, 土地利用类型多为丘陵农业类型, 常见物种有黑斑细蜉 (Caenis nigropunctata)、纹石蛾属 (Hydropsyche sp.) 、狭耳夢卜螺(Radix tagotis); 下游平原区, 土地开发程度较高, 人为干扰程度较高, 主要分 布耐污种类群, 比如霍甫水丝蚓 (Limnodrilus hoffmeisteri)、三带环足摇蚊 (Cricotopus trifasciatus)、梯形多足摇 蚊( Polypedilum scalaenum).

其中直接收集者 51 种, 占 $42.5 \%$; 过滤收集者 10 种, 占 $8.3 \%$; 刮食者 21 种, 占 $17.5 \%$; 斯食者 8 种, 占 $6.7 \%$; 捕食者 30 种, 占 $25 \%$. 直接收集者分布最为广泛, 全流域都有分布; 过滤收集者主要分布在太子河源 头以及北支、清河、沙松河、葠窝水库、汤河、二道河、兰河 源头等支流; 刮食者分布相对较广, 主要分布在太子河中 上游、下游部分区域以及汤河、兰河、细河等支流; 斯食者 相对出现较少, 仅在小汤河、兰河、清河等站位出现, 且所 占比例较少; 捕食者主要分布在太子河中上游, 特别是太 子河本溪段分布最多.

水环境因子主成分分析 (PCA) 表明 (附录 1), 主要 的水环境因子为溶解氧、电导率、水温、高锰酸钾盐指数、 总氮、氨氮; 进一步对主要的水环境物理因子和化学因子 进行偏相关分析 (PCT) ( 附录 2), 分析篮选得到溶解氧、 电导率、总氮、氨氮进人典范对应分析 (CCA).

由偏相关耖选得到的水环境因子与大型底栖动物群 落进行 CCA 分析, 结果显示 (附录 3),4 个轴的特征值 $(\lambda)$ 依次为 $0.410 、 0.241 、 0.190$ 和 0.144 , 在 4 个轴上物种 与环境的相关系数分别为 $0.801 、 0.742 、 0.771$ 和 0.651 , 分别解释了 $41.7 \%$ 、66.1\%、85.4\% 和 $100 \%$ 物种与环境变 异方差的累计量; 根据 CCA 分析结果得出太子河栖境水 环境驱动因子是溶解氧 $(P=0.0245)$ 、电导率 $(P=$ $0.0001)$ 和总氮 $(P=0.0002)$ (附录 3 , 图 2).

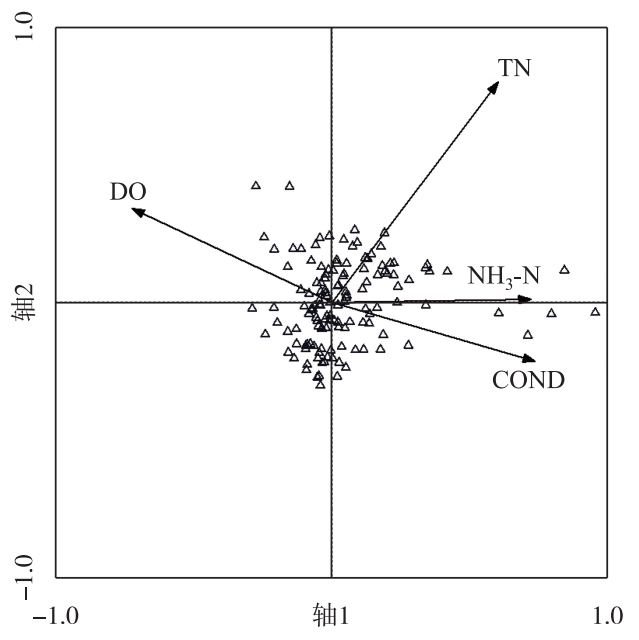

图 2 太子河大型底栖动物群落与水环境 因子的典范对应分析 $(\Delta-$ 采样站位)

Fig. 2 Canonical correspondence analysis ( CCA) of benthic macroinvertebrate community and water environmental factors in Taizi River 


\section{2 大型底栖动物物种水环境驱动因子的最适值和阈值}

水环境驱动因子-溶解氧、电导率、总氮 WA 分析, 结果显示 (表 2): 大型底栖动物物种栖境溶解氧最适 值波动不大, 围绕平均值 $10.82 \mathrm{mg} / \mathrm{L}$, 在 5.99 14.71 mg/L 之间上下波动, 霍甫水丝蚓的溶解氧最适值最低 $(5.99 \mathrm{mg} / \mathrm{L})$, 腹平扁蛭的溶解氧最适值最高 $(14.71 \mathrm{mg} / \mathrm{L})$.

\section{表 2 太子河大型底栖动物物种水环境因子最适值}

Tab.2 Optimal values of water environmental factors for benthic macroinvertebrate species in the Taizi River

\begin{tabular}{|c|c|c|c|c|}
\hline 底栖动物 & 物种 & 溶解氧/ $(\mathrm{mg} / \mathrm{L})$ & 电导率/( $\mu \mathrm{S} / \mathrm{cm})$ & 总氮 $/(\mathrm{mg} / \mathrm{L})$ \\
\hline \multirow[t]{17}{*}{ 昆虫纲 Insecta } & 东方蜉 Ephemera orientalis & 13.26 & 213.42 & 2.58 \\
\hline & 扁蜉科 Heptageniidea & 13.79 & 260.62 & 4.40 \\
\hline & 四节蜉属 Baetis sp. & 10.06 & 219.39 & 2.56 \\
\hline & 何氏高翔蜉 Epeorus herklotsi & 9.20 & 189.26 & 1.91 \\
\hline & 宜兴似动蜉 Cinygmina yixingensis & 10.43 & 228.83 & 1.76 \\
\hline & 细裳蜉科 Leptophlebiidae & 12.06 & 147.08 & 2.04 \\
\hline & 黑翅蜉 Ephemera nigroptera & 10.29 & 294.62 & 0.57 \\
\hline & 纹石蛾属 Hydropsyche sp. & 10.56 & 304.81 & 1.80 \\
\hline & 短脉纹石蛾属 Cheumatopsyche sp. & 10.71 & 272.48 & 2.95 \\
\hline & 角石峨 Stenopsychidae & 9.65 & 178.32 & 1.57 \\
\hline & 异带小突摇文 Micropsectra atrofasciata & 9.89 & 352.67 & 0.89 \\
\hline & 三带环足摇蚊 Cricotopus trifasciatus & 10.94 & 343.80 & 1.05 \\
\hline & 虹属 Tabanus sp. & 12.44 & 290.22 & 2.94 \\
\hline & 毛蠓属 Psychoda sp. & 10.48 & 214.40 & 1.49 \\
\hline & 丝蟌属 Lestes sp. & 9.95 & 542.65 & 2.58 \\
\hline & 海神弓蜓 Macromia clio & 9.08 & 464.19 & 3.98 \\
\hline & 宴蜓属 Aeschna sp. & 12.76 & 233.56 & 3.14 \\
\hline \multirow[t]{4}{*}{ 甲壳纲 Crustacea } & 秀丽白虾 Exopalaemon modestus & 9.49 & 413.54 & 2.61 \\
\hline & 糠虾属 Mysis sp. & 12.87 & 282.90 & 2.36 \\
\hline & 鳞虾属 Acanthomysis sp. & 9.99 & 239.27 & 3.03 \\
\hline & 钩虾属 Gammarus sp. & 13.30 & 300.32 & 0.85 \\
\hline \multirow[t]{5}{*}{ 腹足纲 Gastropoda } & 大耳萝卜螺 Radix auricularia & 9.79 & 316.81 & 2.89 \\
\hline & 狭耳夢卜螺 Radix tagotis & 9.65 & 305.51 & 3.02 \\
\hline & 直缘耳萝卜螺 Radix clessini & 13.73 & 321.68 & 3.93 \\
\hline & 大脐圆扁螺 Hippeutis umibilicalis & 11.44 & 195.85 & 2.94 \\
\hline & 豆螺属 Bithynia sp. & 9.40 & 436.36 & 4.17 \\
\hline \multirow[t]{3}{*}{ 寡毛纲 Oligochaeta } & 霍甫水丝蚓 Limnodrilus hoffmeisteri & 5.99 & 574.34 & 8.36 \\
\hline & 克拉伯水丝蚓 Limnodrilus claparedianus & 10.66 & 404.96 & 3.93 \\
\hline & 苏氏尾鳃蚓 Branchiura sowerbyi & 9.74 & 574.77 & 2.79 \\
\hline \multirow[t]{3}{*}{ 蛭纲 Hirudinea } & 茶色蛭 Haemopis acranulata & 10.31 & 474.63 & 1.43 \\
\hline & 菩氏白勃石蛭 Barbronia weberi & 9.73 & 314.17 & 2.46 \\
\hline & 腹平扁蛭 Glossiphonia complanata & 14.71 & 352.30 & 2.81 \\
\hline
\end{tabular}

大型底栖动物物种栖境电导率最适值范围为 $147.08 \sim 574.77 \mu \mathrm{S} / \mathrm{cm}$, 平均值为 $320.55 \mu \mathrm{S} / \mathrm{cm}$, 细裳蜉科 的电导率最适值最低 $(147.08 \mu \mathrm{S} / \mathrm{cm})$, 苏氏尾鳃蚓的电导率最适值最高 $(574.77 \mu \mathrm{S} / \mathrm{cm})$; 整体来看电导率 最适值波动较大, 最大值和最小值相差 $427.69 \mu \mathrm{S} / \mathrm{cm}$, 其中霍甫水丝蚓、苏氏尾鰓蚓、丝蟌属的电导率最适 值在 $500 \mu \mathrm{S} / \mathrm{cm}$ 以上; 电导率最适值较低的物种有: 何氏高翔蜉、细裳蜉科、角石蛾、大脐圆扁螺.

大型底栖动物物种栖境总氮最适值整体波动较大, 不同类群差异明显, 范围为 $0.57 \sim 8.36 \mathrm{mg} / \mathrm{L}$, 平均值 为 $2.68 \mathrm{mg} / \mathrm{L}$, 黑翅蜉的总氮最适值最低 $(0.57 \mathrm{mg} / \mathrm{L})$, 霍甫水丝蚓的总氮最适值最高 $(8.36 \mathrm{mg} / \mathrm{L})$; 总氮最适 值总体呈现出: 昆虫纲<蛭纲<软甲纲<腹足纲<寡毛纲的趋势. 
太子河栖境水环境因子电导率和总氮对大型底栖动物群落影响相对溶解氧较大, 不同类群电导率和总 氮最适值差异较大; 呈现出敏感种的溶解氧最适值较高, 而耐污种较低; 敏感种的电导率和总氮最适值较 低,耐污种较高的现象.

TITAN 分析, 结果显示 (附录 4, 表 3) : 溶解氧的指示物种有 11 个, 其中与溶解氧國值呈正响应关系的 物种有 7 个, 國值最高的是扁蜉科和大脐圆扁螺, 都为 $19.99 \mathrm{mg} / \mathrm{L}$; 呈负响应关系的物种有 4 个, 阈值最低的 是霍甫水丝蚓, 为 $7.66 \mathrm{mg} / \mathrm{L}$; 其中东方蜉与溶解氧阈值呈正响应关系, 且频率最高, 溶解氧阈值为 $14.89 \mathrm{mg} / \mathrm{L}$, 即栖境溶解氧浓度高于 $14.89 \mathrm{mg} / \mathrm{L}$ 时, 东方蜉密度相对下降; 秀丽白虾与溶解氧阈值呈负响应 关系, 且频率最高, 溶解氧阈值为 $9.09 \mathrm{mg} / \mathrm{L}$, 即栖境溶解氧浓度低于 $9.09 \mathrm{mg} / \mathrm{L}$ 时, 秀丽白虾密度相对稳定.

表 3 太子河大型底栖动物指示物种水环境因子阈值

Tab.3 Threshold of water environmental factors for benthic macroinvertebrate indicator species in the Taizi River

\begin{tabular}{|c|c|c|c|c|c|c|c|}
\hline 水环境因子 & 物种* & 阈值 & 频率 & 响应关系 & 不确定性 & 一致性 & 可靠性 \\
\hline \multirow[t]{11}{*}{ 溶解氧/ $(\mathrm{mg} / \mathrm{L})$} & 东方蜉 & 14.89 & 35 & $\mathrm{z}^{+}$ & 0.01 & 0.99 & 0.96 \\
\hline & 扁蜉科 & 19.99 & 13 & $\mathrm{z}^{+}$ & 0.01 & 0.96 & 0.9 \\
\hline & 何氏高翔蜉 & 9.79 & 24 & $\mathrm{z}^{-}$ & 0.02 & 0.96 & 0.93 \\
\hline & 三带环足摇蚊 & 9.70 & 12 & $\mathrm{z}^{+}$ & 0.01 & 0.96 & 0.93 \\
\hline & 蚈属 & 11.42 & 20 & $\mathrm{z}^{+}$ & 0.02 & 0.99 & 0.91 \\
\hline & 秀丽白虾 & 9.09 & 34 & $\mathrm{z}^{-}$ & 0.01 & 0.99 & 1 \\
\hline & 糠虾属 & 13.65 & 10 & $\mathrm{z}^{+}$ & 0.01 & 0.97 & 0.98 \\
\hline & 狭耳夢卜螺 & 11.72 & 25 & $\mathrm{z}^{-}$ & 0.01 & 0.99 & 0.98 \\
\hline & 直缘耳萝卜螺 & 12.85 & 8 & $\mathrm{z}^{+}$ & 0.01 & 0.98 & 0.93 \\
\hline & 大脐圆扁螺 & 19.99 & 12 & $\mathrm{z}^{+}$ & 0.02 & 1 & 0.95 \\
\hline & 霍甫水丝蚓 & 7.66 & 7 & $\mathrm{z}^{-}$ & 0.01 & 1 & 0.98 \\
\hline \multirow[t]{9}{*}{ 电导率/ ( $\mu \mathrm{S} / \mathrm{cm})$} & 东方蜉 & 240.45 & 35 & $\mathrm{z}^{-}$ & 0.01 & 1 & 1 \\
\hline & 扁蜉科 & 125.90 & 13 & $\mathrm{z}^{-}$ & 0.01 & 0.97 & 0.96 \\
\hline & 四节蜉属 & 283.40 & 33 & $\mathrm{z}^{-}$ & 0.01 & 1 & 0.98 \\
\hline & 细裳蜉科 & 94.70 & 13 & $\mathrm{z}^{-}$ & 0.01 & 1 & 0.99 \\
\hline & 角石峨 & 215.90 & 9 & $\mathrm{z}^{-}$ & 0.01 & 1 & 0.99 \\
\hline & 毛蠓属 & 270.43 & 12 & $\mathrm{z}^{-}$ & 0.01 & 1 & 0.95 \\
\hline & 大脐圆扁螺 & 203.50 & 12 & $\mathrm{z}^{-}$ & 0.01 & 1 & 0.98 \\
\hline & 霍甫水丝蚓 & 645.00 & 7 & $\mathrm{z}^{+}$ & 0.01 & 0.99 & 0.97 \\
\hline & 苏氏尾鳃蚓 & 541.00 & 7 & $\mathrm{z}^{+}$ & 0.01 & 1 & 1 \\
\hline \multirow[t]{6}{*}{ 总氮 $/(\mathrm{mg} / \mathrm{L})$} & 黑翅蜉 & 0.72 & 7 & $\mathrm{z}^{-}$ & 0.01 & 1 & 1 \\
\hline & 三带环足摇蚊 & 0.61 & 12 & $\mathrm{z}^{-}$ & 0.01 & 0.97 & 1 \\
\hline & 秀丽白虾 & 0.81 & 34 & $\mathrm{z}^{+}$ & 0.02 & 0.98 & 0.99 \\
\hline & 钩虾属 & 0.73 & 16 & $\mathrm{z}^{-}$ & 0.02 & 1 & 0.97 \\
\hline & 狭耳萝卜螺 & 1.48 & 25 & $\mathrm{z}^{+}$ & 0.02 & 1 & 0.96 \\
\hline & 霍甫水丝蚓 & 5.39 & 7 & $\mathrm{z}^{+}$ & 0.01 & 1 & 0.99 \\
\hline
\end{tabular}

* 各水环境因子指示的物种; 阈值 (env.cp) :50\% 分位数物种生态阈值; 频率 (freq): 物种出现的频率; 响应关系 (maxgrp): 物种与环境因子响应关系, $\mathrm{z}+$ 表示正响应关系, $\mathrm{z}$-表示负响应关系; 不确定性 (obsiv.prob): 自举重抽样分析得到突变点的 概率; 一致性 (purity) : 自举重抽样分析中与观察的突变点响应方向的一致性; 可靠性 (reliability): 自举重抽样分析得到突 变点的可靠性.

电导率的指示物种有 9 个, 其中与电导率阈值呈正响应关系的物种有 2 个, 國值最高的是霍甫水丝蚓, 为 $645.00 \mu \mathrm{S} / \mathrm{cm}$; 呈负响应关系的物种有 7 个, 阈值最低的是细裳蜉科, 为 $94.70 \mu \mathrm{S} / \mathrm{cm}$; 其中东方蜉与电导 率阈值呈负响应关系, 且频率最高, 电导率阈值为 $240.45 \mu \mathrm{S} / \mathrm{cm}$, 即栖境电导率低于 $240.45 \mu \mathrm{S} / \mathrm{cm}$ 时, 东方 蜉密度相对稳定.

总氮的指示物种有 6 个, 其中与总氮阈值呈正响应关系的物种有 3 个, 國值最高的是霍甫水丝蚓, 为 
$5.39 \mathrm{mg} / \mathrm{L}$; 呈负响应关系的物种有 3 个, 國值最低的是三带环足摇蚊, 为 $0.61 \mathrm{mg} / \mathrm{L}$; 其中秀丽白虾与总氮阈 值呈正响应关系, 且频率最高, 总氮阈值为 $0.81 \mathrm{mg} / \mathrm{L}$, 即栖境总氮高于 $0.81 \mathrm{mg} / \mathrm{L}$ 时, 秀丽白虾密度相对下 降; 钩虾属与总氮阈值呈负响应关系, 且频率最高, 总氮阈值为 $0.73 \mathrm{mg} / \mathrm{L}$, 即栖境总氮低于 $0.73 \mathrm{mg} / \mathrm{L}$ 时, 钩 虾属密度相对稳定.

\section{3 大型底栖动物群落不同多样性水平水环境驱动因子的最适值和阈值}

根据太子河每个站位大型底栖动物 Shannon-Wiener 指数的数值, 将太子河流域水生态调查的 136 个站位 分 4 个多样性水平, 对各区间进行栖境水环境驱动因子 WA 分析, 结果显示 (表 4): 大型底栖动物群落多样性 水平 Shannon-Wiener 指数( 0-1] 区间的溶解氧最适值最低, 为 $10.13 \mathrm{mg} / \mathrm{L}$, 而电导率和总氮最适值最高, 分别 为 $375.56 \mu \mathrm{S} / \mathrm{cm}$ 和 $3.49 \mathrm{mg} / \mathrm{L}$; (3-4] 区间的溶解氧最适值最高, 为 $13.80 \mathrm{mg} / \mathrm{L}$, 而电导率和总氮最适值最低, 分别为 $155.23 \mu \mathrm{S} / \mathrm{cm}$ 和 $2.10 \mathrm{mg} / \mathrm{L}$; (1-2] 区间和(2-3] 区间的溶解氧、电导率和总氮最适值分别位于最大值 和最小值中间. 各组电导率和总氮最适值排序为: (0-1]区间 $<(1-2]$ 区间 $<(2-3]$ 区间 $<(3-4]$ 区间, 结果明显 可以看出: 在一定范围内溶解氧浓度越高, 电导率和总氮浓度越低, 大型底栖动物群落生物多样性水平越高.

表 4 太子河大型底栖动物群落多样性水平 Shannon-Wiener 指数各区间水环境因子最适值

Tab.4 Optimal value of water environment factors for the different Shannon-Wiener index interval of benthic macroinvertebrate in the Taizi River

\begin{tabular}{cccc}
\hline 群落多样性水平 & 溶解氧 $/(\mathrm{mg} / \mathrm{L})$ & 电导率 $/(\mu \mathrm{S} / \mathrm{cm})$ & 总氮 $/(\mathrm{mg} / \mathrm{L})$ \\
\hline $\begin{array}{c}\text { (Shannon-Wiener 指数区间 }) \\
(0-1] \text { 区间 }\end{array}$ & 10.13 & 375.56 & 3.49 \\
$(1-2]$ 区间 & 11.56 & 340.00 & 2.89 \\
$(2-3]$ 区间 & 10.67 & 324.22 & 2.68 \\
$(3-4]$ 区间 & 13.80 & 155.23 & 2.10 \\
\hline
\end{tabular}

TITAN 分析结果显示 (附录 5, 表 5): 大型底栖动物群落多样性水平 Shannon-Wiener 指数 (0-1] 区间与 溶解氧國值呈负响应关系, 而与电导率和总氮阈值呈正响应关系; (1-2] 区间、(2-3]区间、(3-4] 区间与溶

表 5 太子河大型底栖动物群落多样性水平 Shannon-Wiener 指数各区间水环境因子阈值

Tab.5 Threshold of water environmental factors for the different Shannon-Wiener index interval of benthic macroinvertebrate in the Taizi River

\begin{tabular}{|c|c|c|c|c|c|c|c|}
\hline \multirow{2}{*}{$\begin{array}{c}\text { 水环境 } \\
\text { 因子 }\end{array}$} & 群落多样性水平 & \multirow{2}{*}{ 阈值 } & \multirow{2}{*}{ 频率 } & \multirow{2}{*}{ 响应关系 } & \multirow{2}{*}{ 不确定性 } & \multirow{2}{*}{ 一致性 } & \multirow{2}{*}{ 可靠性 } \\
\hline & (Shannon-Wiener 指数区间) & & & & & & \\
\hline \multirow[t]{4}{*}{ 溶解氧 $/(\mathrm{mg} / \mathrm{L})$} & (0-1]区间 * & 10.06 & 43 & $\mathrm{z}^{-}$ & 0.02 & 0.96 & 0.93 \\
\hline & (1-2]区间 & 11.51 & 53 & $\mathrm{z}^{+}$ & 0.01 & 0.93 & 0.98 \\
\hline & （2-3]区间 & 9.79 & 35 & $\mathrm{z}^{+}$ & 0.12 & 0.52 & 0.78 \\
\hline & （3-4]区间 & 11.14 & 5 & $\mathrm{z}^{+}$ & 0.03 & 0.97 & 0.74 \\
\hline \multirow[t]{4}{*}{ 电导率/ ( $\mu \mathrm{S} / \mathrm{cm})$} & $(0-1]$ 区间 $*$ & 272.00 & 43 & $\mathrm{z}^{+}$ & 0.02 & 0.99 & 0.94 \\
\hline & (1-2]区间 & 252.50 & 53 & $\mathrm{z}^{-}$ & 0.11 & 0.73 & 0.74 \\
\hline & (2-3]区间 & 292.00 & 35 & $\mathrm{z}^{-}$ & 0.10 & 0.72 & 0.58 \\
\hline & (3-4]区间* & 135.40 & 5 & $\mathrm{z}^{-}$ & 0.01 & 1.00 & 0.92 \\
\hline \multirow[t]{4}{*}{ 总氮/( mg/L) } & (0-1]区间 & 3.99 & 43 & $\mathrm{z}^{+}$ & 0.01 & 0.66 & 1.00 \\
\hline & (1-2]区间 & 2.34 & 53 & $\mathrm{z}^{-}$ & 0.16 & 0.73 & 0.55 \\
\hline & (2-3]区间 & 3.37 & 35 & $\mathrm{z}^{-}$ & 0.07 & 0.44 & 0.73 \\
\hline & (3-4]区间 & 0.70 & 5 & $\mathrm{z}^{-}$ & 0.12 & 0.83 & 0.47 \\
\hline
\end{tabular}

* 各水环境因子指示的 Shannon-Wiener 指数区间; 阈值 (env.cp): $50 \%$ 分位数 Shannon-Wiener 指数区间生态阈值; 频率 (freq): Shannon-Wiener 指数各区间出现的频率; 响应关系 (maxgrp): Shannon-Wiener 指数各区间与环境因子响应关系, $\mathrm{z}+$ 表示正响应关系, $\mathrm{z}$-表示负响应关系; 不确定性 (obsiv.prob)、一致性(purity)、可靠性( reliability):具体含义同表 3 注释. 
解氧阈值呈正响应关系, 而与电导率和总氮呈负响应关系. 其中溶解氧指示的是 $(0-1]$ 区间, 电导率指示的 是 (0-1 ] 区间和 (3-4] 区间, 且 (0-1 ] 区间与电导率阈值呈正响应关系, 阈值为 $272.00 \mu \mathrm{S} / \mathrm{cm}$, 即栖境电导 率高于 $272.00 \mu \mathrm{S} / \mathrm{cm}$ 时, 大型底栖动物多样性指数较低; (3-4] 区间与电导率阈值呈负响应关系, 阈值为 $135.40 \mu \mathrm{S} / \mathrm{cm}$, 即栖境电导率低于 $135.40 \mu \mathrm{S} / \mathrm{cm}$ 时, 大型底栖动物群落多样性水平较高.

\section{4 大型底栖动物功能摄食类群水环境驱动因子的最适值和阈值}

根据大型底栖动物摄食类型将太子河大型底栖动物分为 5 个功能摄食类群, 由 WA 分析可知 (表 6 ): 直 接收集者的溶解氧最适值最低, 为 $9.96 \mathrm{mg} / \mathrm{L}$, 撕食者的溶解氧最适值最高, 为 $11.44 \mathrm{mg} / \mathrm{L}$; 呈现出直接收集 者<刮食者<过滤收集者<捕食者<撕食者的规律. 电导率最适值最低和最高分别是过滤收集者和直接收集 者, 分别为 $253.47 、 348.12 \mu \mathrm{S} / \mathrm{cm}$; 呈现出直接收集者>捕食者>刮食者 >撕食者 >过滤收集者的规律. 总氮最 适值最低和最高分别是刮食者和直接收集者, 分别为 1.80 和 $3.40 \mathrm{mg} / \mathrm{L}$; 呈现出直接收集者 $>$ 捕食者 $>$ 过滤收 集者>撕食者>刮食者的规律. 总体来看大型底栖动物不同功能摄食类群栖境最适值差异明显, 其中直接收 集者的溶解氧最适值在 5 个功能摄食类群中最低, 而电导率和总氮最适值最高; 撕食者在 5 个功能摄食类群 中溶解氧最适值最高, 而电导率和总氮最适值相对较低.

表 6 太子河大型底栖动物功能摄食类群环境因子最适值

Tab.6 Optimal values of water environmental factors for benthic macroinvertebrate feeding functional groups in the Taizi River

\begin{tabular}{lccc}
\hline 功能摄食类群 $(\mathrm{FFGs})$ & 溶解氧 $/(\mathrm{mg} / \mathrm{L})$ & 电导率 $/(\mu \mathrm{S} / \mathrm{cm})$ & 总氮 $/(\mathrm{mg} / \mathrm{L})$ \\
\hline 直接收集者 $(\mathrm{GC})$ & 9.96 & 348.12 & 3.40 \\
过滤收集者 $(\mathrm{FC})$ & 10.46 & 253.47 & 1.90 \\
刮食者 $(\mathrm{SC})$ & 10.31 & 285.52 & 1.80 \\
撕食者 $(\mathrm{SH})$ & 11.44 & 258.45 & 1.89 \\
捕食者 $(\mathrm{PR})$ & 10.55 & 310.37 & 2.36 \\
\hline
\end{tabular}

大型底栖动物 5 个功能摄食类群栖境水环境驱动因子 TITAN 分析结果显示 (附录 6 , 表 7): : 溶解氧指示 大型底栖动物功能摄食类群为撕食者, 与溶解氧阈值呈正响应关系频率为 37 , 阈值为 $10.14 \mathrm{mg} / \mathrm{L}$; 即栖境溶 解氧高于 $10.14 \mathrm{mg} / \mathrm{L}$ 时, 大型底栖动物撕食者类群密度发生突变, 密度相对下降.

电导率指示大型底栖动物功能摄食类群为过滤收集者、刮食者、撕食者、捕食者, 且与电导率阈值均呈 负响应关系, 频率分别为 $60 、 91 、 37 、 84$, 阈值分别为 $253.00 、 446.03 、 253.00 、 222.00 \mu \mathrm{S} / \mathrm{cm}$; 即栖境电导率低 于 $253.00 \mu \mathrm{S} / \mathrm{cm}$ 时, 过滤收集者和撕食者类群密度相对稳定; 栖境电导率低于 $446.03 \mu \mathrm{S} / \mathrm{cm}$ 时, 刮食者类 群密度相对稳定; 栖境电导率低于 $222.00 \mu \mathrm{S} / \mathrm{cm}$ 时, 捕食者类群密度相对稳定.

总氮指示大型底栖动物功能摄食类群为过滤收集者、刮食者、撕食者, 且与总氮阈值均呈负响应关系, 频率分别为 $60 、 91 、 37$, 阈值分别为 $2.19 、 2.96 、 2.20 \mathrm{mg} / \mathrm{L}$; 即栖境总氮低于 $2.19 \mathrm{mg} / \mathrm{L}$, 过滤收集者类群密度 相对稳定; 栖境总氮低于 $2.96 \mathrm{mg} / \mathrm{L}$, 刮食者类群密度相对稳定; 栖境总氮低于 $2.20 \mathrm{mg} / \mathrm{L}$, 撕食者类群密度 相对稳定.

\section{3 讨论}

\section{1 大型底栖动物群落结构特征及水环境驱动因子}

太子河共鉴定得到大型底栖动物 120 属 (种), 与其他相关研究相一致 ${ }^{[30]}$; 研究表明, 大型底栖动物物 种与栖境环境因子的响应程度的差异, 其分布具有较强的区域性 ${ }^{[31]}$; 太子河上游至下游, 随着海拔高度的下 降, 人为活动的增加, 水体营养盐浓度增加, 溶解氧浓度降低, 生境多样性降低 ${ }^{[32]}$; 本研究调查显示, 敏感种 (EPT) 类多分布于太子河上游, 而耐污种中下游分布比例较高.

CCA 结果表明, 溶解氧、电导率和总氮是大型底栖动物群落栖境关键的水环境驱动因子; 在巢湖流域的 研究发现, 影响大型底栖动物群落结构的水环境驱动因子是电导率、总氮、氨氮、硝酸盐 ${ }^{[33]}$; 对洞庭湖大型底 栖动物的研究表明, 主要的水环境驱动因子是溶解氧和水温 ${ }^{[34]}$; 对太湖的研究发现, 电导率是影响大型底栖 
动物群落结构的水环境驱动因子 ${ }^{[35]}$; 此外, 国外的关于大型底栖动物群落水环境驱动因子的相关研究也基 本类似 ${ }^{[36-38]}$. 因此, 分析溶解氧、电导率和总氮的最适值和阈值具有重要的研究意义.

表 7 太子河大型底栖动物功能摄食类群水环境因子阈值

Tab.7 Threshold of water environmental factors for benthic macroinvertebrate feeding functional groups in the Taizi River

\begin{tabular}{|c|c|c|c|c|c|c|c|}
\hline 水环境因子 & 功能摄食类群 (FFGs) & 阈值 & 频率 & 响应关系 & 不确定性 & 一致性 & 可靠性 \\
\hline \multirow[t]{5}{*}{ 溶解氧 $/(\mathrm{mg} / \mathrm{L})$} & 直接收集者 (GC) & 8.52 & 113 & $\mathrm{z}^{-}$ & 0.10 & 0.81 & 0.61 \\
\hline & 过滤收集者( FC) & 7.85 & 60 & $\mathrm{z}+^{+}$ & 0.04 & 0.86 & 0.83 \\
\hline & 刮食者(SC) & 8.62 & 91 & $\mathrm{z}^{+}$ & 0.01 & 0.74 & 1.00 \\
\hline & 撕食者 $(\mathrm{SH}) *$ & 10.14 & 37 & $\mathrm{z}+$ & 0.01 & 1.00 & 0.96 \\
\hline & 捕食者(PR) & 9.00 & 84 & $\mathrm{z}^{+}$ & 0.03 & 0.60 & 0.87 \\
\hline \multirow[t]{5}{*}{ 电导率/( $\mu \mathrm{S} / \mathrm{cm})$} & 直接收集者( GC) & 398.30 & 113 & $\mathrm{z}^{-}$ & 0.24 & 0.76 & 0.62 \\
\hline & 过滤收集者 (FC) * & 253.00 & 60 & $\mathrm{z}^{-}$ & 0.01 & 1.00 & 1.00 \\
\hline & 刮食者 $(\mathrm{SC}) *$ & 446.03 & 91 & $\mathrm{z}^{-}$ & 0.01 & 0.99 & 1.00 \\
\hline & 撕食者 $(\mathrm{SH}) *$ & 253.00 & 37 & $\mathrm{z}^{-}$ & 0.01 & 1.00 & 1.00 \\
\hline & 捕食者(PR) * & 222.00 & 84 & $\mathrm{z}^{-}$ & 0.02 & 0.97 & 0.95 \\
\hline \multirow[t]{5}{*}{ 总氮/( mg/L) } & 直接收集者( GC) & 0.72 & 113 & $\mathrm{z}^{-}$ & 0.03 & 0.84 & 0.83 \\
\hline & 过滤收集者 $(\mathrm{FC})^{*}$ & 2.19 & 60 & $\mathrm{z}^{-}$ & 0.01 & 0.97 & 0.99 \\
\hline & 刮食者 $(\mathrm{SC}) *$ & 2.96 & 91 & $\mathrm{z}^{-}$ & 0.01 & 1.00 & 1.00 \\
\hline & 撕食者 $(\mathrm{SH}) *$ & 2.20 & 37 & $\mathrm{z}^{-}$ & 0.01 & 0.99 & 0.96 \\
\hline & 捕食者(PR) & 3.33 & 84 & $\mathrm{z}^{-}$ & 0.01 & 0.65 & 1.00 \\
\hline
\end{tabular}

* 各水环境因子指示的功能摄食类群; 阈值 (env.cp): $50 \%$ 分位数功能摄食类群生态阈值; 频率 (freq) : 各功能摄食类群出 现的频率; 响应关系 (maxgrp) : 功能摄食类群与环境因子响应关系, $\mathrm{z}+$ 表示正响应关系, $\mathrm{z}-$ 表示负响应关系; 不确定性 (obsiv.prob)、一致性( purity)、可靠性( reliability) : 具体含义同表 3 注释.

\section{2 影响大型底栖动物群落结构特征的水环境因子最适值分析}

大型底栖动物不同的物种类群溶解氧、电导率和总氮最适值差异较大; 其中溶解氧最适值最低的是霍 甫水丝蚓, 为 $5.99 \mathrm{mg} / \mathrm{L}$, 溶解氧最适值最高的是腹平扁蛭, 为 $14.71 \mathrm{mg} / \mathrm{L}$; 电导率最适值最低的是细裳蜉科, 为 $147.08 \mu \mathrm{S} / \mathrm{cm}$, 电导率最适值最高的是苏氏尾鳃蚓, 为 $574.77 \mu \mathrm{S} / \mathrm{cm}$; 总氮最适值最低的是黑翅蜉, 为 $0.57 \mathrm{mg} / \mathrm{L}$, 总氮最适值最高的是霍甫水丝蚓, 为 $8.36 \mathrm{mg} / \mathrm{L}$. 研究表明, 流域栖境溶解氧较高的区域 EPT 类 物种分布较高 ${ }^{[39]}$, 电导率可降低敏感种的出现频率 ${ }^{[12]}$, 表明大型底栖动物群落敏感种更适宜于溶解氧浓度 较高、电导率和总氮浓度较低的环境中, 这与本研究结果一致. Duan 等 ${ }^{[11]}$ 研究显示, 在严重污染的区域, 总 氮浓度非常高, 物种丰富度较低, 只有耐污种 (寡毛纲和摇蚊类) 才能存活; 同时电导率较高的区域分布的大 型底栖动物基本都是耐污种,表明在电导率和总氮较高的区域耐污种分布较高.

大型底栖动物群落多样性水平 Shannon-Wiener 指数 (0-1] 区间的溶解氧最适值最低, 为 $10.13 \mathrm{mg} / \mathrm{L}$, 而 电导率和总氮最适值最高, 分别为 $375.56 \mu \mathrm{S} / \mathrm{cm}$ 和 $3.49 \mathrm{mg} / \mathrm{L} ;(3-4]$ 区间的溶解氧最适值最高, 为 13.80 $\mathrm{mg} / \mathrm{L}$, 而电导率和总氮最适值最低, 分别为 $155.23 \mu \mathrm{S} / \mathrm{cm}$ 和 $2.10 \mathrm{mg} / \mathrm{L} ;(1-2]$ 区间和 (2-3] 区间的溶解氧、 电导率和总氮最适值分别位于最大值和最小值中间; 结果表明, 在一定范围内溶解氧浓度越高, 电导率和总 氮浓度越低, 大型底栖动物群落 Shannon-Wiener 指数越高, 群落多样性水平越高. 大型底栖动物的群落物种 丰度和生物多样性随着溶解氧、氮磷化合物以及悬浮有机物的浓度而变化 ${ }^{[40]}$, 总氮是水体富营养化的主要 因素, 富营养化往往会导致大型底栖动物群落生物多样性的降低 ${ }^{[33]}$; 在溶解氧浓度较低的环境会增加毒害 物质硫化物的浓度, 导致生物多样性的降低 ${ }^{[41]}$.

直接收集者的溶解氧最适值最低, 为 $9.96 \mathrm{mg} / \mathrm{L}$, 撕食者的溶解氧最适值最高, 为 $11.44 \mathrm{mg} / \mathrm{L}$; 电导率最 适值最低和最高分别是过滤收集者和直接收集者, 分别为 $253.47 、 348.12 \mu \mathrm{S} / \mathrm{cm}$; 总氮的最适值最低和最高 分别是刮食者和直接收集者, 分别为 $1.80 、 3.40 \mathrm{mg} / \mathrm{L}$; 总体来看大型底栖动物不同功能摄食类群栖境最适值 差异明显, 其中直接收集者的溶解氧最适值在 5 个功能摄食类群中最低, 而电导率和总氮最适值最高; 在 5 
个功能摄食类群中撕食者的溶解氧最适值最高, 而电导率和总氮最适值相对较低. 本研究显示, 直接收集者 占整个类群的 $64.7 \%$; 由于摇蚊属和水丝蚛属适宜溶解氧浓度较低、电导率和总氮浓度较高的环境 ${ }^{[42]}$, 所以 直接收集者对环境耐受程度较高; 而且直接收集者以底质有机物颗粒为食, 溶解氧浓度较低的缓流环境有 利于有机物颗粒的降解和沉积 ${ }^{[43]}$, 适宜直接收集者的生存. 总氮浓度较高的环境呈现出, 过滤收集者、刮食 者、撕食者和捕食者的密度大幅度减少, 而直接收集者成为优势群体, 甚至达到 $100 \%$ 的趋势 ${ }^{[11,44]}$; 撕食者全 部是水生昆虫类,适宜溶解氧浓度较高、电导率和总氮浓度相对较低的环境.

\section{3 影响大型底栖动物群落结构特征的水环境因子阈值分析}

大型底栖动物群落各物种与水环境因子的阈值响应关系以及响应程度不同; 敏感种类群的溶解氧國值 高于耐污种类群以及其他类群; 溶解氧的指示物种中, 呈正响应关系且阈值最高的是扁蜉和大脐圆扁螺, 都 为 $19.99 \mathrm{mg} / \mathrm{L}$; 呈负响应关系且阈值最低的是霍甫水丝蚂, 为 $7.66 \mathrm{mg} / \mathrm{L}$; 电导率的指示物种中, 呈正响应关 系且阈值最高的是霍甫水丝蚓, 为 $645.00 \mu \mathrm{S} / \mathrm{cm}$; 呈负响应关系且阈值最低的是细裳蜉科, 为 $94.70 \mu \mathrm{S} / \mathrm{cm}$; 总氮的指示物种中, 呈正响应关系且阈值最高的是霍甫水丝蚓, 为 $5.39 \mathrm{mg} / \mathrm{L}$; 呈负响应关系且阈值较低的 是黑翅蜉, 为 $0.72 \mathrm{mg} / \mathrm{L}$. 研究表明, 河流水环境状态决定大型底栖动物群落的丰富度和分布格局 ${ }^{[31]}$, 敏感种 类群适宜在水质状况较好, 溶解氧浓度较高的水环境中, 而耐污种对栖境的耐受能力较高, 在富营养化且极 度缺氧的状态下摇蚊幼虫、霍甫水丝蚓和苏氏尾鳃蚓也能生存 ${ }^{[13]}$, 支持本研究结果.

溶解氧指示的是大型底栖动物群落多样性水平 Shannon-Wiener 指数 (0-1] 区间; 电导率指示的是 $(0-$ 1] 区间和 (3-4] 区间, 且 (0-1] 区间与电导率阈值呈正响应关系, 阈值为 $272.00 \mu \mathrm{S} / \mathrm{cm},(3-4)$ 区间与电导 率阈值呈负响应关系, 國值为 $135.40 \mu \mathrm{S} / \mathrm{cm}$; 大型底栖动物群落多样性水平最高的 (3-4] 区间溶解氧阈值相 对较高, 电导率和总氮阈值最低, 且均呈现出负响应关系; 结果表明, 溶解氧浓度较高、电导率和总氮浓度较 低的栖境中大型底栖动物群落多样性水平较高. 研究表明, 在低氧水平的水环境中, 水质质量、食物质量的 下降、呼吸机制的干扰以及其他形态生理学特征等, 致使大型底栖动物密度的降低 ${ }^{[45-46]}$. 本研究中总氮没有 指示大型底栖动物群落多样性水平, 但也具有重要的参考价值, 其中在多样性水平最高的 Shannon-Wiener 指数 (3-4] 区间, 总氮的阈值很低, 且呈负响应相关, 即随着总氮浓度的降低, 大型底栖动物群落生物多样性 升高; 一般而言, 电导率和总氮较高的水体, 富营养化严重, 大型底栖动物多样性水平与水体营养化程度呈 负相关 ${ }^{[35]}$, 与本研究结果相一致.

溶解氧指示的功能摄食类群为撕食者, 与溶解氧阈值呈正响应关系, 國值为 $10.14 \mathrm{mg} / \mathrm{L}$; 溶解氧较高的 环境中流域底部落叶枯枝的降解较快, 减少了撕食者的食物来源, 在一定程度上制约了撕食者的生存 ${ }^{[47]}$. 电导率指示的大型底栖动物功能摄食类群为过滤收集者、刮食者、撕食者、捕食者, 且与电导率阈值均呈负 响应关系, 阈值最低的是捕食者, 为 $222.00 \mu \mathrm{S} / \mathrm{cm}$; 研究表明, 电导率是水环境因子的一个重要指数 ${ }^{[12]}$, 反映 水体溶解离子的浓度 ${ }^{[48]}$; 电导率与人为干扰程度呈正相关关系 ${ }^{[49]}$, 是导致大型底栖动物群落结构退化的重 要指标 ${ }^{[12]}$. 总氮是水体富营养化的主要因素之一, 水体富营养化会导致大型底栖动物群落结构稳定性降 低 ${ }^{[13]}$, 有研究结果显示, 撕食者种数与总氮浓度呈负相关, 撕食者和刮食者对扰动也比较敏感, 直接收集者 和过滤收集者, 则更耐受污染 ${ }^{[11]}$; 总氮指示的功能摄食类群为过滤收集者、刮食者、撕食者,且与总氮阈值均 呈负响应关系,阈值最低的是过滤收集者.

\section{4 流域大型底栖动物环境因子适宜性量化分析的科学价值}

河流生境状态很大程度上决定了水生生物的群落结构特征 ${ }^{[00-51]}$; 不同的物种或类群对河流环境压力因 素的响应关系和响应程度不同 ${ }^{[52]}$; 因此,本研究通过分析大型底栖动物群落水环境因子的最适值和阈值, 探 究大型底栖动物群落水环境适宜性的需求, 确定维持大型底栖动物群落结构稳定的水环境状态, 为太子河 流域生态修复、污染物控制提供准确的科学依据. 我们还将开展太子河鱼类、着生藻、浮游动植物等水生生 物水环境驱动因子的最适值和阈值的研究, 综合各水生生物类群对适宜水环境的需求水平, 最终分析、评估 得出水环境驱动因子的控制量, 以指导太子河污染物总量的控制以及生态修复. 基于水生生物群落探究水 生生物群落水环境因子的最适值和阈值, 分析水生生物群落栖息地适宜性的潜力和局限性, 量化水生生物 群落生存以及维持生物多样性和功能的栖息水环境的需求水平, 构建河流污染物总量控制体系, 营造健康 的河流生态环境, 将是未来河流生态治理和修复的关键环节. 


\section{4 附录}

附录见电子版( DOI: 10.18307/2019.0604).

\section{5 参考文献}

[ 1 ] Frissell CA, Liss WJ, Warren CE et al. A hierarchical framework for stream habitat classification: Viewing streams in a watershed context. Environmental Management, 1986, 10(2) : 199-214. DOI: 10.1007/BF01867358.

[ 2 ] Zheng BH, Zhang Y, Li YB. Study of indicators and methods for river habitat assessment of Liao River Basin. Acta Scientiae Circumstantiae, 2007, 27(6): 928-936. [郑丙辉, 张远, 李英博. 辽河流域河流栖息地评价指标与评价方法研 究. 环境科学学报, 2007, 27(6): 928-936.]

[ 3 ] Zhao JY, Dong ZR, Sun DY. State of the art in the field of river habitat assessment. Science \& Technology Review, 2008, 26(17) : 82-88. [ 赵进勇, 董哲仁, 孙东亚. 河流生物栖息地评估研究进展. 科技导报, 2008, 26(17) : 82-88. ]

[ 4 ] Geist J. Integrative freshwater ecology and biodiversity conservation. Ecological Indicators, 2011, 11 (6) : 1507-1516. DOI: $10.1016 /$ j.ecolind.2011.04.002.

[ 5 ] Li LJ, Zhang J, Wu D et al. Relationships between structure and diversity of fish functional groups and land use in the Taizi River. Acta Ecologica Sinica, 2017, (20) : 221-232. DOI: 10.5846/stxb201608181693. [李丽娟, 张吉, 吴丹等. 太 子河流域鱼类功能群结构与多样性对土地利用类型的响应. 生态学报, 2017, (20): 221-232.]

[ 6 ] Li LJ, Jin W, Wang BH et al. Relationship between land use types within riparian zones and community structure of diatom in Taizi River, China. Research of Environmental Sciences, 2015, 28(11) : 1662-1669. [李丽娟, 金文, 王博涵等. 太 子河河岸带土地利用类型与硅藻群落结构的关系. 环境科学研究, 2015, 28(11) : 1662-1669.]

[ 7 ] Yin XW, Xu ZX, Gao X et al. Macrobenthos community structure and its relationships with environmental factors in Weihe River basin, Northwest China. Chinese Journal of Applied Ecology, 2013, 24(1): 218-226. [殷旭旺, 徐宗学, 高欣等. 渭河流域大型底栖动物群落结构及其与环境因子的关系. 应用生态学报, 2013, 24(1) : 218-226.]

[ 8 ] Zhang Y, Dudgeon D, Cheng D et al. Impacts of land use and water quality on macroinvertebrate communities in the Pearl River drainage basin, China. Hydrobiologia, 2010, 652 (1) : 71-88. DOI: 10.1007/s10750-010-0320-x.

[ 9 ] Chapin FS, Schulze ED, Mooney HA. Biodiversity and ecosystem processes. Trends in Ecology \& Evolution, 1997,26 (8) : 571-577. DOI: 10.1016/0169-5347(92)90141-W.

[10] Donohue I, Jackson AL, Irvine PK. Nutrient enrichment homogenizes lake benthic assemblages at local and regional scales. Ecology, 2009, 90(12) : 3470-3477. DOI: 10.2307/25660992.

[11] Duan XH, Wang ZY, Xu MZ. Effects of fluvial processes and human activities on stream macro-invertebrates. International Journal of Sediment Research, 2011, 26(4) : 416-430. DOI: 10.1016/s1001-6279(12)60002-x.

[12] Zhang Y, Ding S, Zhao Q et al. Exploring the feasibility of establishing conductivity criteria for macroinvertebrate based on the field investigations. Asian Journal of Ecotoxicology, 2015, 10 ( 1 ): 204-214. DOI: 10. 7524/AJE. 1673-5897. 20140531002. [张远, 丁森, 赵茜等. 基于野外数据建立大型底栖动物电导率水质基准的可行性探讨. 生态毒理学 报, 2015, 10(1): 204-214.]

[13] Gong ZJ, Xie P, Tang HJ et al. The influence of eutrophycation upon community structure and biodiversity of macrozoobenthos. Acta Hydrobiologica Sinica, 2001, 25(3) : 210-216. [龚志军, 谢平, 唐汇涓等. 水体富营养化对大型底栖动 物群落结构及多样性的影响. 水生生物学报, 2001, 25(3): 210-216.]

[14] Braak CJFT, Prentice C, Ter Braak CJF. A theory of gradient analysis. Advances in Ecological Research, 1988,18 (2004) : 271-317. DOI: 10.1016/S0065-2504(08)60183-X.

[15] Zheng WH, QU XD, Zhang Y et al. Habitat suitability of macroinvertebrates in the Taizi River Basin, Northeast China. Research of Environmental Sciences, 2011, (12): 1355-1363. [郑文浩, 渠晓东, 张远等. 太子河流域大型底栖动物 栖境适宜性. 环境科学研究, 2011, (12) : 1355-1363.]

[16] Konrad CP. Simulating the recovery of suspended sediment transport and river-bed stability in response to dam removal on the Elwha River, Washington. Ecological Engineering, 2009, 35(7) : 1104-1115. DOI: 10.1016/j.ecoleng.2009.03.018.

[17] Wu DH, Yu HY, Wu HY et al. Estimation of river nutrients thresholds based on benthic macroinvertebrate assemblages: A case study in the upper reaches of Xitiao Stream in Zhejiang, China. Chinese Journal of Applied Ecology, 2010, 21(2): 483-488. [ 吴东浩, 于海燕, 吴海燕等. 基于大型底栖无脊椎动物确定河流营养盐浓度阈值一以西苕溪上游流 
域为例. 应用生态学报, 2010, 21(2): 483-488.]

[18] Tang T, Ren Z, Tang T et al. Total nitrogen and total phosphorus thresholds for epilithic diatom assemblages in inflow tributaries of the Three Gorges Reservoir, China. Chinese Journal of Applied Ecology, 2016, 27 (8) : 2670-2678. DOI: 10. 13287/j.1001-9332.201608.010. [汤婷, 任泽, 唐涛等. 基于附石硅藻的三峡水库人库支流氮、磷阈值. 应用生态学 报, 2016, 27(8):2670-2678.]

[19] Baker ME, King RS. A new method for detecting and interpreting biodiversity and ecological community thresholds. Methods in Ecology \& Evolution, 2010, 1(1) : 25-37. DOI: 10.1111/j.2041-210X.2009.00007.x.

[20] Groffman PM, Baron JS, Blett T et al. Ecological thresholds: The key to successful environmental management or an important concept with no practical application? Ecosystems, 2006, 9(1) : 1-13. DOI: 10.1007/s10021-003-0142-z.

[21] Zou W, Li TM, Liu L et al. Macrozoobenthic community structure and water quality assessment of Lake Luoma, Jiangsu Province, China. J Lake Sci, 2017, 29(5) : 1177-1187. DOI: 10.18307/2017.0515. [邹伟, 李太民, 刘利等. 苏北骆 马湖大型底栖动物群落结构及水质评价. 湖泊科学, 2017, 29(5): 1177-1187.]

[22] Jiang WX, Cai QH, Tang T et al. The functional feeding group ecology of macroinvertebrate in Xiangxi River system. Acta Ecologica Sinica, 2009, 29(10) : 5207-5218. [蒋万祥, 蔡庆华, 唐涛等. 香溪河水系大型底栖动物功能摄食类群生 态学. 生态学报, 2009, 29(10): 5207-5218.]

[23] Min WW, Han J, Yin XW et al. Quantitative relationships among the diatom community and driving factors in Taizi River Basin, China. Research of Environmental Sciences, 2016, 29(5):672-679. [闵文武, 韩洁, 殷旭旺等. 太子河流域硅 藻群落与驱动因子的定量关系. 环境科学研究, 2016, 29(5): 672-679.]

[24] Liu YY, Zhang WZ, Wang YX eds. Economic Fauna of China: Freshwater Mollusca. Beijing: Science Press, 1979. [刘 月英, 张文珍, 王跃先等. 中国经济动物志 ·淡水软体动物. 北京: 科学出版社, 1979.]

[25] Morse JC, Yang LF, Tian LX eds. Aquatic insects of china useful for monitoring water quality. Nanjing: Hohai University Press, 1994.

[26] Wang JC, Wang XH eds. Northern China Chironomus larva. Beijing: Yanshi Press in China, 2011. [王俊才, 王新华. 中 国北方摇蚊幼虫. 北京: 中国言实出版社, 2011.]

[27] "Monitoring and analysis method of water and wastewater" editorial board of State Environmental Protection Administration of China ed. Monitoring and analysis method of water and wastewater: Fourth Edition. Beijing: China Environmental Science Press, 2002. [ 国家环境保护总局《水和废水监测分析方法》编委会. 水和废水监测分析方法: 第 4 版. 北京: 中国环境科学出版社, 2002.]

[28] Cummins KW. Structure and function of stream ecosystems. Bioscience, 1974, 24 (11): 631-641. DOI: 10. 2307/1296676.

[29] Deng PY, Zhang W, Wang XT et al. The effects of water quality on epilithic diatoms communities of Dongjiang river basin. Acta Ecologica Sinica, 2015, 35(6) : 1852-1861. [邓培雁, 张婉, 王旭涛等. 水质对东江流域附生硅藻群落的影响. 生态学报, 2015, 35(6): 1852-1861.]

[30] Qu XD, Zhang Y, Ma SQ et al. Spatial distribution characteristics of macroinvertebrate communities in Taizi River Basin. Research of Environmental Sciences, 2013, 26(5): 509-515. [ 渠晓东, 张远, 马淑芹等. 太子河流域大型底栖动物群 落结构空间分布特征. 环境科学研究, 2013, 26(5) : 509-515.]

[31] Pedersen ML, Friberg N, Skriver J et al. Restoration of Skjern River and its valley-Short-term effects on river habitats, macrophytes and macroinvertebrates. Ecological Engineering, 2007, 30(2) : 145-156. DOI: 10.1016/j. ecoleng. 2006. 08.009 .

[32] Wang YT, Zhang Y, Gao X et al. Analysis of fish community distribution and its relationship with environmental factors in different freshwater eco-regions of Taizi River Basin. Research of Environmental Sciences, 2016, 29(2) : 192-201. [王云 涛, 张远, 高欣等. 太子河流域不同水生态区鱼类群落分布与环境因子的关联性. 环境科学研究, 2016, 29(2): 192-201.]

[33] Zhang Y, Cheng L, Yin HB et al. Benthic macroinvertebrate community structure and environmental determinants in river systems of Chaohu Basin. J Lake Sci, 2017, 29(1) : 200-215. DOI: 10.18307/2017.0122. [张又, 程龙, 尹洪斌等. 巢 湖流域不同水系大型底栖动物群落结构及影响因素. 湖泊科学, 2017, 29(1): 200-215.]

[34] Wang CM, Zhang Y, Shi HH et al. Macrozoobenthic community structure and bioassessment of water quality in Lake Dongting, China. J Lake Sci, 2016, 28(2) : 395-404. DOI: 10.18307/2016.0220. [王丑明, 张屹, 石慧华等. 洞庭湖 大型底栖动物群落结构和水质评价. 湖泊科学, 2016, 28(2): 395-404.] 
[35] Xu H, Cai YJ, Tang XM et al. Community structure of macrozoobenthos and the evaluation of water environment in Lake Taihu. J Lake Sci, 2015, 27(5): 840-852. DOI: 10.18307/2015.0510. [许浩, 蔡永久, 汤祥明等. 太湖大型底栖动 物群落结构与水环境生物评价. 湖泊科学, 2015, 27(5): 840-852.]

[36] Kimmel WG, Argent DG. Community concordance between fishes and benthic macroinvertebrates among adventitious and ordinate tributaries of a major river system. Ecological Indicators, 2016, 70 : 15-22. DOI: 10.1016/j.ecolind.2016.05.037.

[37] Hill MJ, Death RG, Mathers KL et al. Macroinvertebrate community composition and diversity in ephemeral and perennial ponds on unregulated floodplain meadows in the UK. Hydrobiologia, 2017, 793(1) : 95-108. DOI: 10.1007/s10750-0162856-x.

[38] Kalogianni E, Vourka A, Karaouzas I et al. Combined effects of water stress and pollution on macroinvertebrate and fish assemblages in a Mediterranean intermittent river. Science of the Total Environment, 2017, 603/604: 639-650. DOI: 10. 1016/j. scitotenv.2017.06.078.

[39] Zhang Y, Cheng L, Tolonen KE et al. Substrate degradation and nutrient enrichment structuring macroinvertebrate assemblages in agriculturally dominated Lake Chaohu Basins, China. Science of the Total Environment, 2018, 627(15) : 57-66. DOI: 10.1016/j.scitotenv.2018.01.232.

[40] Camargo JA. Macrobenthic surveys as a valuable tool for assessing freshwater quality in the Iberian Peninsula. Environmental Monitoring \& Assessment, 1993, 24(1) : 71-90. DOI: 10.1007/BF00568800.

[41] De Jonge M, Dreesen F, De Paepe J et al. Do acid volatile sulfides (AVS) influence the accumulation of sediment-bound metals to benthic invertebrates under natural field conditions? Environmental Science \& Technology, 2009, 43(12) : 45104516. DOI: $10.1021 / \mathrm{es} 8034945$.

[42] Zhang Y, Ding S, Zhang Y et al. Effects of land use on macroinvertebrate functional feeding groups in Taizi River Basin. Research of Environmental Sciences, 2018, 31(9): 1527-1536. [张亚, 丁森, 张远等. 太子河流域土地利用对大型底 栖动物功能摄食类群的影响. 环境科学研究, 2018, 31(9): 1527-1536.]

[43] Mérigoux S, Dolédec S. Hydraulic requirements of stream communities: A case study on invertebrates. Freshwater Biology, 2004, 49(5) : 600-613. DOI: 10.1111/j.1365-2427.2004.01214.x.

[44] Xu M, Wang Z, Duan X et al. Effects of pollution on macroinvertebrates and water quality bio-assessment. Hydrobiologia, 2014, 729(1) : 247-259. DOI: 10.1007/s10750-013-1504-y.

[45] Riens JR, Schwarz MS, Mustafa F et al. Aquatic macroinvertebrate communities and water quality at buffered and nonbuffered wetland siteson federal waterfowl production areas in the rainwater basin, Nebraska. Wetlands, 2013, 33 (6) : 1025-1036. DOI: 10.1007/s13157-013-0460-7.

[46] Miserendino ML, Archangelsky M, Brand C et al. Environmental changes and macroinvertebrate responses in Patagonian streams (Argentina) to ashfall from the Chaitén Volcano (May 2008). Science of the Total Environment, 2012, 424: 202212. DOI: $10.1016 / \mathrm{j}$.scitotenv.2012.02.054.

[47] Miserendino ML, Masi CI. The effects of land use on environmental features and functional organization of macroinvertebrate communities in Patagonian low order streams. Ecological Indicators, 2010, 10 ( 2 ) : 310-319. DOI: 10. 1016/j. ecolind.2009.06.008.

[48] Liu ZG. Impacts of rubber dan on water quality and macroinvertebrate[Dissertation]. Tangshan: Hebei United University, 2011. [刘志刚. 橡胶坝对河流水质及大型底栖动物的影响 [学位论文]. 唐山: 河北联合大学, 2011.]

[49] Geng SW. Scale effect of landuse on the macroinvertebrate within river corridor[Dissertation]. Hangzhou: Zhejiang University of Technology, 2012. [耿世伟. 河流廊道尺度效应对大型底栖动物群落影响研究 [ 学位论文]. 杭州: 浙江工业 大学, 2012.]

[50] Turley MD, Bilotta GS, Chadd RP et al. A sediment-specific family-level biomonitoring tool to identify the impacts of fine sediment in temperate rivers and streams. Ecological Indicators, 2016, 70: 151-165. DOI: 10.1016/j. ecolind. 2016. 05.040 .

[51] Nicola GG, Almodóvar A, Elvira B. Effects of environmental factors and predation on benthic communities in headwater streams. Aquatic Sciences, 2010, 72(4) : 419-429. 10.1007/s00027-010-0145-8.

[52] Johnson RK, Furse MT, Hering D et al. Ecological relationships between stream communities and spatial scale: implications for designing catchment-level monitoring programmes. Freshwater Biology, 2007, 52(5) : 939-958. DOI: 10.1111/j. 1365-2427.2006.01692.x. 


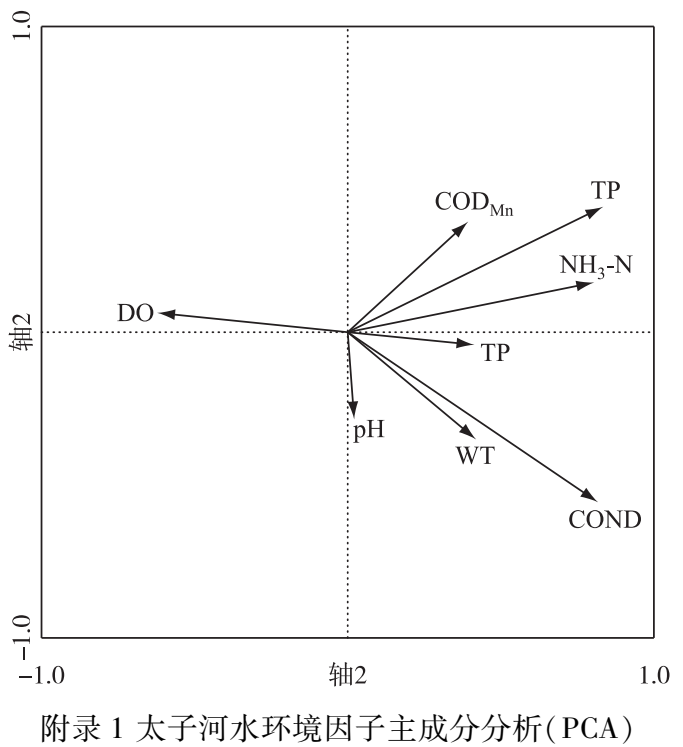

( WT-水温; $\mathrm{pH}$-酸碱度; COND-电导率; DO-溶解氧; $\mathrm{COD}_{\mathrm{Mn}}$-高锰酸钾盐指数; $\mathrm{NH}_{3}-\mathrm{N}$-氨氮; $\mathrm{TN}$-总氮; $\mathrm{TP}$-总磷)

Appendix 1 Principal component analysis (PCA) of water environment factors in the Taizi River

附录 2 太子河水环境因子间的偏相关分析 ( PCT)

Appendix 2 Partial correlation tests ( PCT) among water environment factors in the Taizi River

\begin{tabular}{|c|c|c|c|c|c|}
\hline 项目 & 水温 & 电导率 & 溶解氧 & 高锰酸钾盐指数 & 氨氮 \\
\hline 电导率 & $0.456^{* * * *}$ & 1 & & & \\
\hline 溶解氧 & $-0.508^{* * * *}$ & $-0.436^{* * * *}$ & 1 & & \\
\hline 高锰酸钾盐指数 & 0.204 & $0.207^{*}$ & $-0.248^{* *}$ & 1 & \\
\hline 氨氮 & $0.246^{* *}$ & $0.603^{\text {**** }}$ & $-0.383^{* * * *}$ & $0.374^{* * *}$ & 1 \\
\hline 总氮 & $0.223^{* *}$ & $0.651^{\text {**** }}$ & $-0.362^{* * * *}$ & $0.238^{* *}$ & $0.789^{\text {**** }}$ \\
\hline
\end{tabular}

*表示 $P<0.05$; ** 表示 $P<0.01 ; * * *$ 表示 $P<0.001$.

附录 3 太子河大型底栖动物功能摄食类群与水环境因子 CCA 分析结果

Appendix 3 Results of CCA analysis of macroinvertebrate FFGs-water environmental factors in the Taizi River

\begin{tabular}{lcccc}
\hline 项目 & 轴 1 & 轴 2 & 轴 3 & 轴 4 \\
\hline 特征值 & 0.410 & 0.241 & 0.190 & 0.144 \\
物种与环境的关系 & 0.801 & 0.742 & 0.771 & 0.651 \\
物种变量累计/\% & 1.7 & 2.8 & 3.6 & 4.2 \\
物种与环境变量累计/\% & 41.7 & 66.1 & 85.4 & 100.0 \\
电导率 $(\mathrm{COND})$ & 0.6462 & -0.1202 & 0.3739 & -0.1937 \\
溶解氧 $(\mathrm{DO})$ & -0.4511 & 0.4221 & 0.4242 & 0.1550 \\
氨氮 $\left(\mathrm{NH}_{3}-\mathrm{N}\right)$ & 0.6239 & 0.0727 & 0.0775 & 0.3928 \\
总氮 $(\mathrm{TN})$ & 0.6052 & 0.4762 & -0.1021 & -0.0057 \\
\hline
\end{tabular}



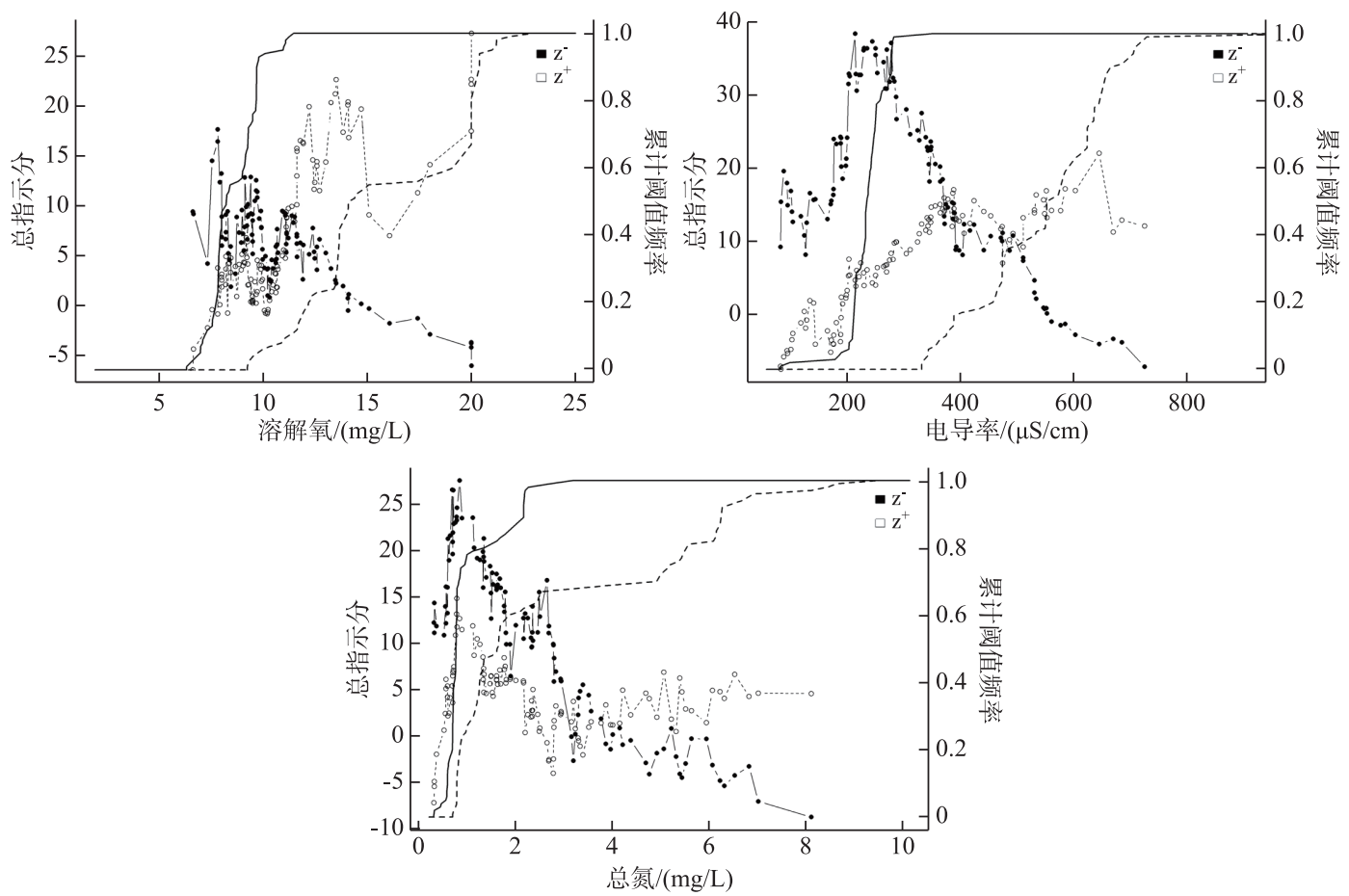

附录 4 大型底栖动物物种 TITAN 分析正响应 $\left(\mathrm{z}^{-}\right)$和负响应 $\left(\mathrm{z}^{+}\right)$对候选水环境驱动因子突变点的响应曲线

(Unfiltered Sum $(\mathrm{z})$ : 总指示分;Cumulative Frequency: 累计阈值频率;实线和虚线分别表示大型底栖 动物物种对候选水环境驱动因子正响应 $\left(\mathrm{z}^{-}\right)$和负响应 $\left(\mathrm{z}^{+}\right) 100$ 个自举抽样的突变点点的累积频率分布 $)$

Appendix 4 TITAN analysis of positive response $\left(z^{-}\right)$and negative response $\left(z^{+}\right)$to mutation points of candidate water environmental driving factors by macroinvertebrate species 

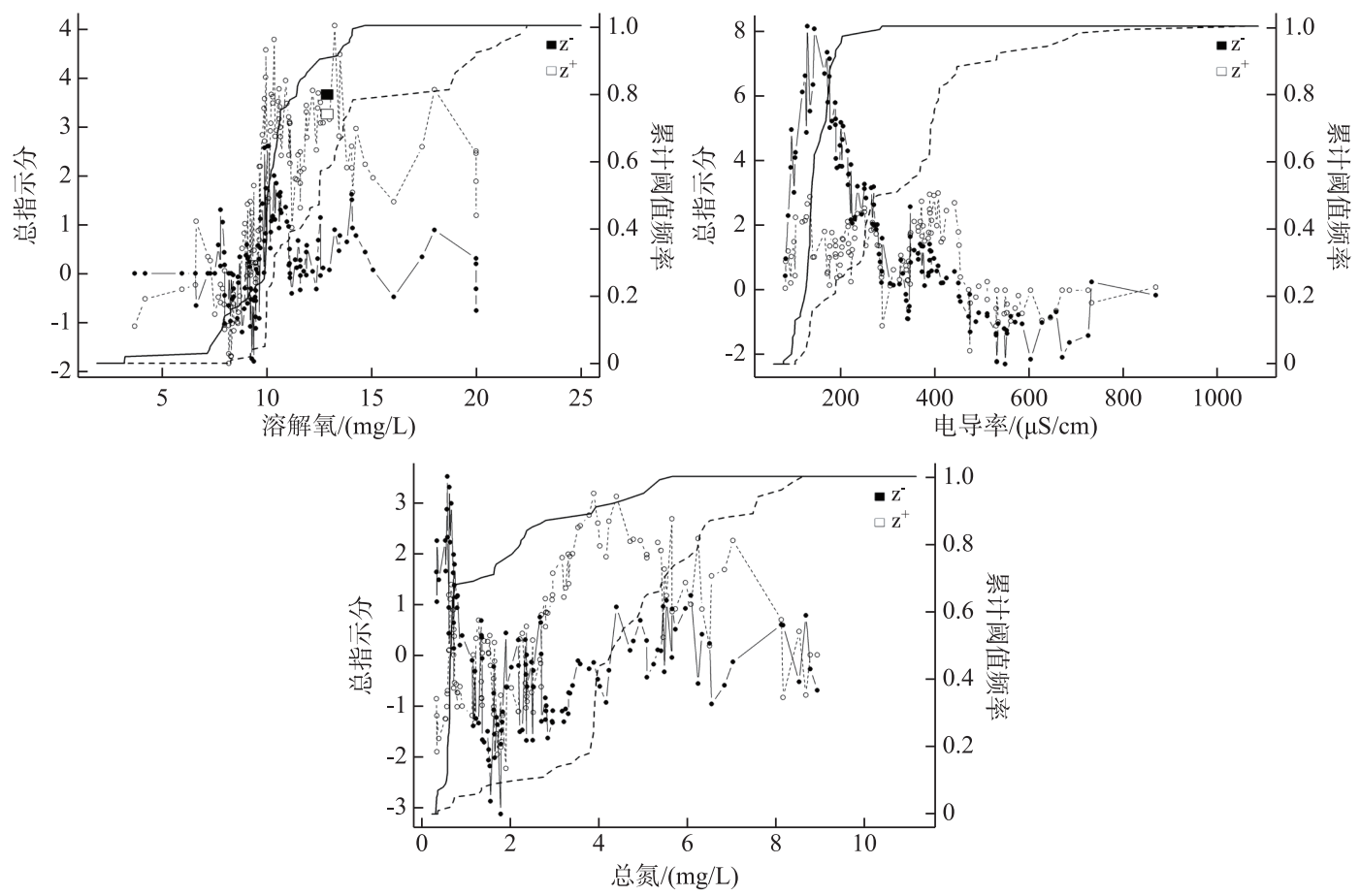

附录 5 大型底栖动物 Shannon-Wiener 多样性指数分类区间 TITAN 分析正响应 $\left(\mathrm{z}^{+}\right)$和负响应 $\left(\mathrm{z}^{-}\right)$

对候选水环境驱动因子突变点的响应曲线 (Unfiltered Sum $(\mathrm{z})$ : 总指示分; Cumulative Frequency:

累计阈值频率; 实线和虚线分别表示大型底栖动物 Shannon-Wiener 多样性指数分类区间对候选水环境 驱动因子正响应 $(\mathrm{z}-)$ 和负响应 $(\mathrm{z}+) 100$ 个自举抽样的突变点点的累积频率分布)

Appendix 5 TITAN analysis of positive response $\left(\mathrm{z}^{+}\right)$and negative response $\left(\mathrm{z}^{-}\right)$to mutation points of candidate water environmental driving factors in the macroinvertebrate

Shannon-Wiener diversity index classification group 

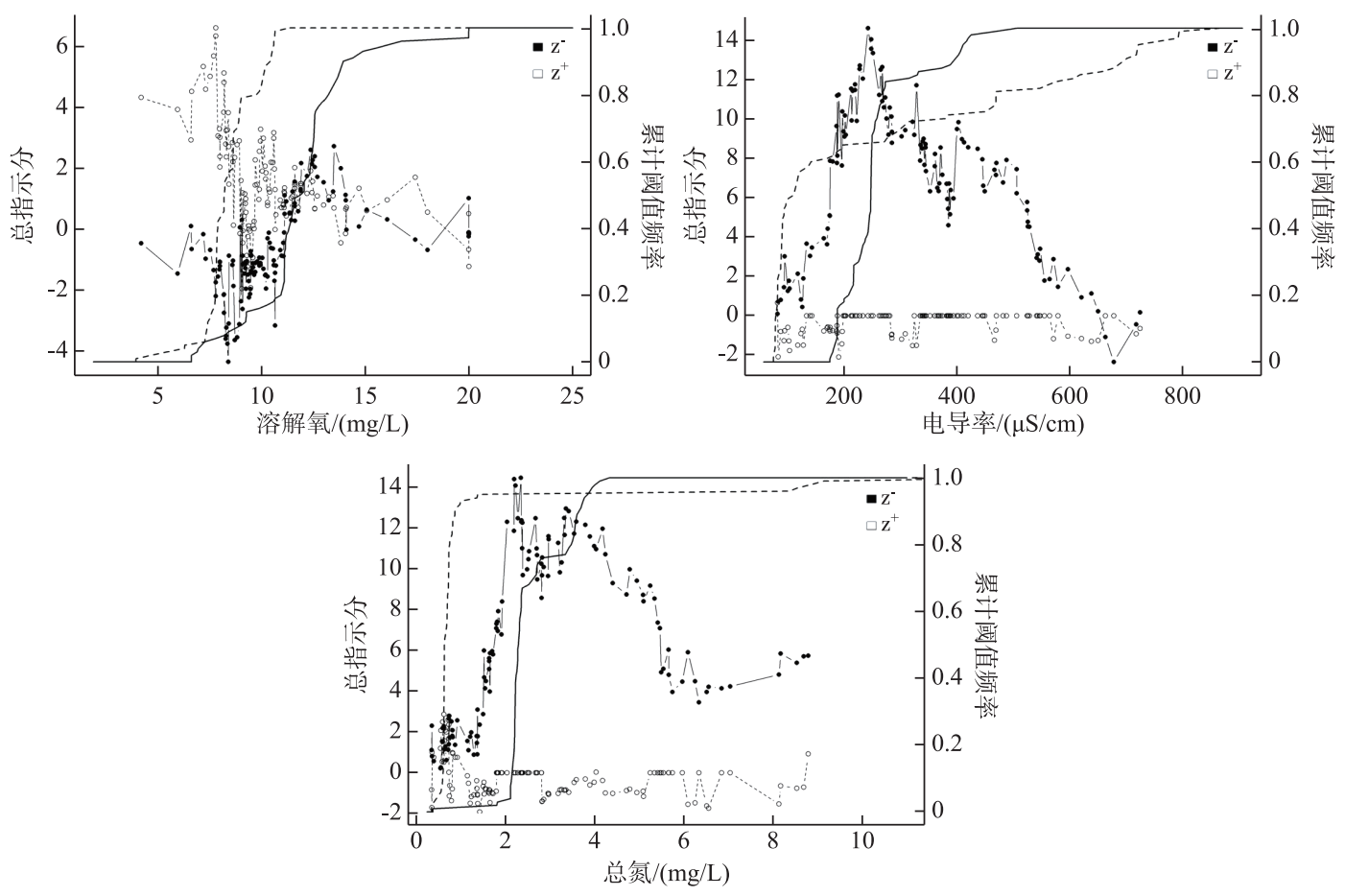

附录 6 大型底栖动物功能摄食类群 TITAN 分析正响应 $\left(\mathrm{z}^{+}\right)$和负响应 $\left(\mathrm{z}^{-}\right)$

对候选水环境驱动因子突变点的响应曲线 (Unfiltered Sum $(\mathrm{z})$ : 总指示分;

Cumulative Frequency: 累计阈值频率; 实线和虚线分别表示大型底栖动物摄食

功能群对候选水环境驱动因子正响应 $\left(\mathrm{z}^{-}\right)$和负响应 $\left(\mathrm{z}^{+}\right) 100$ 个自举抽样的突变点点的累积频率分布)

Appendix 6 TITAN analysis of positive response $\left(\mathrm{z}^{+}\right)$and negative response $\left(\mathrm{z}^{-}\right)$curves of mutation points of candidate water environmental driving factors by macroinvertebrate FFGS 